\title{
Why Do Option Prices Predict Stock Returns? The Role of Price
}

\section{Pressure in the Stock Market}

\author{
Luis Goncalves-Pinto, Bruce D. Grundy, Allaudeen Hameed, \\ Thijs VAN DER HEIJDEN, Yichao ZHU*
}

May 10, 2019

\begin{abstract}
Stock and options markets can disagree about a stock's value because of informed trading in options and/or price pressure in the stock. The predictability of stock returns based on this crossmarket discrepancy in values is especially strong when accompanied by stock price pressure, and it does not depend on trading in options. We argue that option-implied prices provide an anchor for fundamental stock values that helps to distinguish stock price movements due to pressure versus news. Overall, our results are consistent with stock price pressure being the primary driver of the option price-based stock return predictability.
\end{abstract}

JEL Classification: G11, G12, C13

Keywords: Price Pressure, Put-Call Parity, Return Predictability, Informed Trading

*Goncalves-Pinto (lgoncalv@cuhk.edu.hk) is with the Department of Finance at the University of New South Wales and at the Chinese University of Hong Kong. Grundy (bruceg@unimelb.edu.au) is with the Department of Finance, University of Melbourne. Hameed (allaudeen@nus.edu.sg) is with the Department of Finance, National University of Singapore. Van der Heijden (thijsv@unimelb.edu.au) is with the Department of Finance, University of Melbourne. Zhu (yichao.zhu@anu.edu.au) is with the Research School of Finance, Actuarial Studies and Statistics, Australian National University. For helpful comments and suggestions, we thank Zhi Da, Miguel Ferreira, Terry Hendershott, Frank Liu, Roni Michaely, Lars Norden, Neil Pearson, Pedro Santa-Clara, Tao Shu, Tyler Shumway, Elvira Sojli, David Weinbaum, Chen Zhao, two anonymous reviewers and an anonymous associate editor, participants at the ABFER Conference, the Asian Finance Association Meetings, the FIRN Conference, the FMA Asia-Pacific Conference, the OptionMetrics Research Conference, the SFS Cavalcade, and seminar participants at BI Norwegian Business School, Deakin University, Goethe-University Frankfurt, Monash University, Nova School of Business and Economics, RMIT, Tilburg University, Chinese University of Hong Kong, City University of Hong Kong, University of Hong Kong, University of Melbourne, University of New South Wales, University of Warwick, and University of Western Australia. We thank Tarun Chordia for generously sharing the NYSE order imbalance data. This research is supported by an Inquire Europe project grant. Goncalves-Pinto gratefully acknowledges financial support from Singapore MOE AcRF Tier-1 Grant No. R-315-000-109-112. Hameed acknowledges financial support from NUS AcRF Tier 1 Grant R-315-000-124-115. Previous versions of this paper were circulated as "Under Pressure: Identifying Temporary Stock Mispricing Using Option Markets" and "Informed Trading in Options or Price Pressure in Stocks? Connecting the DOTS in Option-Based Return Predictability". 


\section{Introduction}

Stock and options markets can be viewed as disagreeing about a stock's value when the stock price implied by put-call parity differs from the price at which the stock is trading. The value discrepancy between the two markets can be driven by two distinct mechanisms. First, informed investors may prefer to trade in the options market because of options' implicit leverage or because of shorting constraints in the stock market. This can lead to option prices signaling the level to which the stock price will move when it too comes to reflect the information. This is consistent with the results in Cremers and Weinbaum (2010), Xing, Zhang, and Zhao (2010) and An, Ang, Bali, and Cakici (2014) who interpret the ability of option-implied volatility spreads, skews and changes therein to predict future stock returns as evidence that information is reflected in options markets before being fully impounded into stock prices. These studies conclude that the options market is informationally superior to the stock market.

We argue that the results reported in the existing literature are consistent with a second mechanism which has not yet been adequately examined. Specifically, there may be price pressure in the stock market that is not reflected in option prices. When the value discrepancy is driven by stock price pressure, option prices signal the level to which stock prices will revert when the price pressure subsides. In this event, the option price-based predictability of stock returns is driven by liquidity effects in the stock market and not by faster price discovery in the options market. Since the stock market is generally more liquid than the option market, the idea that the cross market predictability comes from stock price pressure is not obvious. We undertake a comprehensive examination of the price pressure and information mechanisms in generating option price-based predictability in stock returns.

To operationalize our investigation, we start with the put-call parity relation to estimate the option-implied value of the stock and then create a measure of the difference between 
the option-implied stock value and the traded stock price, which we denote as DOTS. The DOTS measure is positive (negative) when the option-implied value is greater than (less than) the traded stock price; i.e., when the stock has experienced downward (upward) price pressure and/or when the option price reflects positive (negative) information not reflected in the stock price. We show that DOTS effectively contains the same information as the existing stock return predictors based on implied volatilities and has the advantage of being model-free and therefore easier to interpret.

Figure 1(a) illustrates the information-based explanation of a positive DOTS value, namely that informed investors who receive a positive signal about the stock on day $t-1$ bid up the prices of calls relative to puts. This in turn increases the option-implied value of the stock and creates the positive DOTS value on day $t-1$. Then, as the information becomes reflected in the stock market, the traded stock price adjusts on day $t$ to the new (higher) fundamental value and the day- $t$ stock return is positive.

[Figure 1 about here]

Figure 1(b) illustrates the alternative mechanism whereby the same positive DOTS value on day $t-1$ is generated by selling pressure in the stock market not reflected in option prices. As the selling pressure subsides on day $t$, the traded stock price reverts to its fundamental value. Analogous information and price pressure explanations are applicable when a negative DOTS value is observed. Hence, DOTS is a simple measure that captures the combined effects of price pressure in the stock market and the relative informational efficiency of the options and stock markets. In line with findings in the existing literature, we find that when portfolios are formed based on DOTS, the spread in risk-adjusted returns between value-weighted portfolios of stocks in the high versus low DOTS deciles on the day after the portfolio formation date is economically large at $82 \mathrm{bps}$, and statistically significant. 
Figure 1 not only illustrates the two potential causes of option price-based predictability, it also suggests a way to empirically distinguish them by examining the stock and option characteristics that are related to price pressure and informed trading during the formation period. We find that stocks in the extreme DOTS deciles are more illiquid in that they are smaller in market capitalization, have higher bid-ask spreads, and higher Amihud priceimpact measures. Consistent with price pressure, we find that large positive (negative) values for DOTS at time $t-1$ are accompanied by high selling (buying) pressure during the formation day measured by (a) negative (positive) stock returns; (b) abnormally high seller-initiated (buyer-initiated) stock trading activity; and (c) abnormally high stock trading volume. A composite stock price pressure proxy that combines these three measures indicates that returns predicted by DOTS more than double when accompanied by high price pressure. Under the alternative explanation that informed trading in options is the sole driver of option price-based stock return predictability, we should observe no predictability in a sample of stocks with zero trading in their associated options. Yet the predictability remains strong when we restrict our sample to the subset of stocks with zero option trading.

As shown in Figure 1(a), the hypothesis of informed options trading suggests that a large positive (negative) DOTS at time $t-1$ should be accompanied by a positive (negative) change in option-implied values from time $t-2$ to time $t-1$. However, we find that the option-implied returns on the formation day for the high DOTS decile are significantly lower than those for the low DOTS decile, which mirrors the result for stock returns. ${ }^{1}$ Moreover, if informed trading in options were the driver of option price-based predictability, then we should observe informed investors with good news buying calls and writing puts more than they are writing calls and buying puts. In other words, we expect net synthetic long positions in the underlying asset or a positive option order imbalance (negative option order imbalance) when informed investors receive good (bad) news about the stock. We find the

\footnotetext{
${ }^{1}$ An option-implied return is the percent change in an option-implied stock value.
} 
exact opposite. Stocks in the high (low) DOTS decile exhibit a negative (positive) abnormal order imbalance in the options market, implying that on net synthetic shares are being sold (bought).

For holding periods of one week and one month, the long-short risk-adjusted returns based on the extreme DOTS deciles are 81 bps and 96 bps, respectively. If we skip a day between the formation and the holding periods, then the returns decrease to 2 bps for the remaining days of the week, and to 22 bps for the remaining days of the month, with neither of the shorter period returns being statistically different from zero. That the first-day return accounts for most of the weekly and monthly return is consistent with price pressure in the stock market being temporary and with any information reflected in option prices but not in stock prices being quickly impounded into stock prices.

Our main result that DOTS captures temporary deviations of stock prices from fundamental values which then revert appears similar to the findings on short-term stock return reversals in Jegadeesh (1990), Avramov, Chordia, and Goyal (2006), Nagel (2012), and Hameed and Mian (2015). Like our paper, these studies also show that the return reversals weaken when a day is skipped between the formation and holding periods and when returns are computed using bid-ask average prices. ${ }^{2}$

We find that the predictive effect of DOTS has declined in the recent decade, similar to the diminishing return reversal effect over time as reported in Chordia, Subrahmanyam, and Tong (2014). The overlap in findings based on DOTS and short-term reversals supports the price pressure hypothesis emanating from frictions in the stock market. Stock return reversals per se do not explain our findings: reversals for stocks matched on the magnitude of formation day returns in the extreme DOTS deciles are not significant. Since stock returns

\footnotetext{
${ }^{2}$ When the returns on the strategy are computed based on midquote prices, we continue to get statistically significant risk-adjusted returns, but the magnitude reduces substantially to 22 bps for the first holding day. That the mid-quote return is also significant points to the significant impact of stock market frictions on predictability that is more than simply bid-ask bounce.
} 
reflect both news and trading frictions, past returns are a noisy proxy for price pressure. We argue that option-implied stock prices provide an anchor to distinguish price changes that reflect new information from changes that reflect price pressure. This interpretation is also consistent with the evidence we present that predictability based on DOTS is not affected by option trading activity or by changes in quoted option prices.

While our evidence supports the important role of stock price pressure as a driver of option price-based stock return predictability, it does not preclude informed trading in the options market from also playing a role. We examine the relative importance of the two effects in the context of a parsimonious model of stock returns that incorporates stock price pressure and information differences between the two markets. In the model, traded stock returns and option-implied returns are driven by information that is common to both markets as well as by (i) special information that is impounded into option prices before being impounded into stock prices and (ii) stock price pressure that is not fully reflected in option quotes. Our estimates from the model reinforce the argument that the primary driver of the option price-based stock return predictability comes from stock price pressure.

Finally, we examine stock return predictability based on DOTS around scheduled information events, earnings announcements in particular. While earnings announcements can make gathering private information valuable, the accompanying inventory and information asymmetry risks faced by market-makers can also increase stock price pressure. We find that a strategy of going long stocks in the high DOTS decile and going short stocks in the low DOTS decile around earnings announcements generates a large one-day return of 115 bps. More importantly, the strategy's positive announcement return is preceded by a strong negative traded stock return of -157 bps on the day prior to the earnings announcement. This is consistent with price pressure being a significant predictor of stock returns even around earnings announcements. Overall, the cumulative evidence we present points to stock price 
pressure not reflected in option prices being a primary contributor to the option price-based predictability of stock returns.

The relevant extant research is reviewed in Section 2. Section 3 explains the calculation of the option-implied value of a stock and of the DOTS measure of the difference between the option-implied value and the traded stock price. Section 4 describes the data and the characteristics of portfolios formed on the basis of the DOTS measure. Section 5 reports our results on predictability and its link to price pressure in the stock market and informed trading in the options market. Section 6 models and investigates the simultaneous influence of stock price pressure and informed option trading and investigates return predictability around earnings announcements. Section 7 concludes.

\section{Related Research}

\subsection{Theory of informed traders' choice between stock and options}

Easley, O'Hara, and Srinivas (1998) and An et al. (2014) contain two of the principal theoretical models that capture the trading behavior of informed investors when presented with a choice between trading in stock and options. Although Easley et al. is cited as predicting a preference by informed traders to trade in options first, their model does not make such a prediction. Rather, the model predicts that informed traders will either trade in the stock market only or in both markets, with the outcome depending on the relative liquidity of the stock and options markets as well as the degree of leverage provided by options. Options markets do not have an informational advantage over stock markets and any information in the history of stock and option trades is simultaneously reflected in both markets. The paper's empirical investigation observes that frictions associated with order placement and reporting and with the queuing of orders submitted via electronic routing may 
mean that information is reflected in one market before the other but concludes that there is only limited empirical support for directional hypotheses related to information flows.

The two-period analysis in An et al. (2014) is a second model that has been incorrectly cited in the literature as one that shows that information is reflected in option prices before being reflected in stock prices. In the An et al. (2014) analysis, the correlation between the first-period return on a call and the underlying stock's second-period expected dollar price change is positive. This positive correlation is the mechanical outcome of the fact that a high first-period call return occurs when the stock price at the end of the first period has become high. The second-period dollar change in the stock price is the product of this high stock price at the end of the first period and the stock return in the second period. The average second-period dollar change in the stock price is then high by construction and not because information is reflected in the options market before the stock market. In fact, the model is such that information is simultaneously reflected in both markets at the end of the first period. In conclusion, these theoretical models do not imply that stock returns will be predictable based on option prices.

\subsection{Prior empirical evidence of option price-based predictability}

Manaster and Rendleman (1982) examine the prices of a set of options on a stock and invert the Black-Scholes model to back out the implied stock value and implied volatility pair that best fits the observed price of the stock. The subsequent stock return is found to be positively related to the difference between the stock's option-implied value and its traded price or DOTS.

Using the call minus put implied volatility spread (IVS), Cremers and Weinbaum (2010)

document that IVS is a strong predictor of future stock returns. To see the similarity between DOTS and IVS, note that if either good news is reflected in option prices before 
being reflected in stock prices or the traded stock price is under selling pressure, then the implied volatility of a call option will be higher than the implied volatility of a put option with the same strike price and maturity. Figure 2 plots the implied volatilities of European calls and puts written on a non-dividend-paying stock when the prices of the options are determined by the Black-Scholes model evaluated at the stock's fundamental value. When the stock's traded price is equal to its fundamental value and option prices are determined by Black-Scholes, then the implied volatilities of both calls and puts are equal to the true volatility. But when the stock is mispriced, the implied volatility of the call (put) will be an increasing (decreasing) function of the difference between the option-implied value of the stock and its traded price. For the parameter values of Figure 2, a one percent underpricing (overpricing) of the stock will cause the call option-implied volatility to overstate (understate) the true volatility by close to five percent per annum. An analogous bias in the opposite direction applies to the put-option implied volatility.

[Figure 2 about here]

For European options with an exercise price equal to the stock's fundamental value, the IVS calculated using the traded stock price is a direct transformation of DOTS. However, the DOTS measure has the advantage that it directly compares two values for the same asset in two separate markets and thus allows each value to be studied in isolation when analyzing the cause of option price-based stock return predictability. In contrast, IVS is a non-linear combination of the effects of information differences and price pressure in both markets, making its analysis less intuitive.

Cremers and Weinbaum (2010) report that the option-implied volatility spread-based strategy is profitable even after controlling for lagged weekly stock returns. Since lagged returns are a noisy measure of price pressure, controlling for lagged returns provides only a partial control for price pressure. Cremers and Weinbaum also report that predictability is 
higher when stock liquidity is relatively low and option liquidity relatively high, and that there is little predictability when the opposite is true. Consistent with our argument that option priced-based predictability is in part a reflection of stock price pressure, the greater return predictability when stock liquidity is low follows naturally from price pressure being higher for stocks that are less liquid. ${ }^{3,4}$

An et al. (2014) examine the predictability of stock returns given past changes in the implied-volatility spread. The monthly change in IVS (or $(\Delta I V S)$, reflects the change in the differential valuation between the stock and options market and is therefore similar to the change in DOTS over that same period. $\triangle I V S$ is a noisy measure of (the level of) DOTS. As illustrated in Figure IA.1 in Internet Appendix IA, when the stock price is below (above) the option-implied stock value, the implied volatilities of calls (puts) will tend to have increased (decreased) in the recent past, and the subsequent abnormal return on the stock will be positive (negative). An et al. report that the predictive ability of changes in implied-volatility spreads is larger than that of changes in the implied volatilities of either call or put options alone. The greater predictive ability of changes in spreads is to be expected since any change in the true volatility of the underlying will be common to both calls and puts and changes in true volatilities do not predict returns. ${ }^{5}$

\footnotetext{
${ }^{3}$ Other papers that examine the link between IVS and stock returns include Atilgan (2014), Bali and Hovakimian (2009) and Yan (2011). Atilgan (2014) finds that predictability around earnings announcements is higher for less liquid stocks. Bali and Hovakimian (2009) and Yan (2011) argue that IVS proxies for priced jump risk.

${ }^{4} \mathrm{~A}$ similar argument applies to the predictability of stock returns based on option implied volatility skew in Xing et al. (2010), as we illustrate in Internet Appendix IA. Moreover, an alternate explanation for the conclusion of Xing et al. that it takes more than half a year for information reflected in the optionimplied volatility skew to be impounded into stock prices, is that the implied-volatility skew reflects return characteristics that are not well-priced by the Fama-French three-factor model.

${ }^{5} \mathrm{An}$ et al. argue that their abnormal returns are unlikely to be due to any microstructure trading effects implicit in their $\triangle I V S$ measure since they examine returns over the subsequent month. We estimate that the abnormal return to a value-weighted long-short portfolio using stocks in the high and low deciles of DOTS is $82 \mathrm{bps}$ on the day after the portfolio formation date, with a standard error of 12 bps. If daily abnormal returns are independent with a constant standard deviation, and any non-zero expected abnormal return due to microstructure/price pressure effects is limited to the first day after the sorting date, then the expected abnormal return summed over a 20 trading-day month will be 82 bps with an associated one-tailed $p$-value
} 
Note that not all extant empirical analyses conclude that information is first reflected in the options market. Muravyev, Pearson, and Broussard (2013) use high frequency data on a sample of 39 stocks with very liquid options markets to show that, when stock and options markets disagree about the stock's value, it is option quotes that adjust to eliminate the disagreement, and the stock's quotes do not adjust. Muravyev et al. conclude that "option price quotes do not contain economically significant information about future stock prices". Shang (2016) shows that the predictive ability of implied volatility spreads is not diminished when implied volatilities are calculated from the quoted prices of options that did not trade or options with zero open interest and concludes that "the hypothesis that the predictive content in the [implied-volatility] spread reflects the presence of informed trading in options markets is incomplete." 6

\section{Option-Implied Stock Values and Traded Stock Prices}

We first set out the bounds on bid and ask stock prices implied by the put-call parity relation for American options in the presence of option transaction costs. These no-arbitrage bounds are used to develop an option-implied estimate of a stock's fundamental value which, when contrasted with the traded stock price, provides a signal of the combined effects of price pressure in the stock market and the relative informational efficiency of the stock and options markets.

of $6.3 \%$; i.e., monthly returns can reflect microstructure trading effects even if those effects are limited to a single day.

${ }^{6} \mathrm{~A}$ distinct literature focuses on option trading, rather than on option prices as a predictor of stock returns. Amin and Lee (1997), Roll, Schwartz, and Subrahmanyam (2010), Johnson and So (2012) and $\mathrm{Hu}(2014)$ report that various metrics of option trading can predict returns. It should be noted that stock return predictability associated with option trading does not necessarily imply that information is reflected in option prices before being reflected in the stock price. It may be that option trading predicts both future option-implied stock returns and future traded stock returns. Since our focus is the predictive ability of option prices rather than option volume, we do not investigate this last possibility. 


\subsection{No-arbitrage bounds implied by put-call parity}

In the presence of transaction costs, the put-call parity relation for American options provides bounds on a stock's bid and ask prices that depend on the options' bid and ask prices. The put-call parity implied lower bound on a stock's ask price, $S_{a s k}$, is given by

$$
S_{a s k} \geq S^{L} \equiv C_{b i d}+K e^{-r T}-P_{a s k},
$$

where $S^{L}$ is the no-arbitrage lower bound, $C_{b i d}$ is the bid price of an American-style call option with exercise price $K$ and time to maturity $T, P_{a s k}$ is the ask price of an American put with the same exercise price and maturity, and $r$ denotes the continuously compounded risk-free rate. With analogous notation, the upper bound on a stock's bid price is given by

$$
S_{b i d} \leq S^{U} \equiv C_{a s k}+K+P V(\text { Div })-P_{b i d}
$$

where $P V($ Div) denotes the present value of the dividends to be paid on the stock over the option's life. ${ }^{7}$

From (1) and (2) it is clear that the minimum possible difference between $S^{L}$ and $S^{U}$ is the sum of the bid-ask spreads for the call and put options in the pair, that is $\left(C_{a s k}-\right.$ $\left.C_{b i d}\right)+\left(P_{a s k}-P_{b i d}\right)$. This will be the difference if there is no possibility of dividends over the options' life and the risk-free rate is zero. For the sample detailed in Section 4, the

\footnotetext{
${ }^{7}$ The bounds in (1) and (2) are developed in Cox and Rubinstein (1985). Unlike the bounds derived from European options, the lower bound in relation (1) on a stock's ask price implied by put-call parity and American options does not involve the present value of the dividends to be paid over the remaining life of the options. Relation (1) sets out the condition that must be satisfied to preclude arbitrage from a strategy of buying a share, selling a call, borrowing the present value of the exercise price, and buying a put. If the bounds were violated, this strategy would yield an immediate profit. If the American call were exercised against you prior to maturity and the dividends lost to the new owner of the share, the exercise price received would be at least enough to repay the borrowing plus accumulated interest and you will retain both the put and the original profit.
} 
average option bid-ask spread is $\$ 0.25$ and the average stock price equals $\$ 35$. The resulting minimum no-arbitrage price range is an economically meaningful $1.4 \%$ on average.

\subsection{DOTS: Difference between the option-implied stock value and the traded stock price}

The relatively wide no-arbitrage bounds on the stock's bid and ask prices implied by option prices allow for incomplete transmission of shocks between the two markets. Thus, a demand shock in the stock market will not necessarily be propagated to the options market. While stocks are in fixed supply, options contracts can be easily created by traders, implying a relatively higher elasticity of supply in options compared to stocks. Similarly, an information shock which causes informed trading in options and changes option prices will not automatically cause the stock price to change by a commensurate amount. In both cases, the difference between the stock's fundamental value inferred from option prices and the traded stock price will predict future stock returns.

The midpoint of the upper and lower price bounds implied by a call and put option pair provides an estimate of the fundamental value of the underlying stock. ${ }^{8}$ Given the date $t$ prices of a pair of call and put options $j$ written on stock $i$, the difference between the option-implied estimate of fundamental value and the traded stock price, (DOTS) is measured as

$$
D O T S_{i j t}=\frac{\frac{S_{i j t}^{U}+S_{i j t}^{L}}{2}-S_{i t}}{S_{i t}}
$$

where $S_{i t}$ is the stock's closing price and $S_{i j t}^{U}$ and $S_{i j t}^{L}$ are the upper and lower bounds on $S_{i t}$ given by equations (1) and (2). DOTS is positive (negative) when the option-implied

\footnotetext{
${ }^{8}$ Since the lower and upper price bounds are not necessarily symmetric about the fundamental value, the midpoint does not necessarily coincide with the traded price in the absence of frictions. Even then, optionimplied returns will be largely unaffected by any asymmetry unless borrowing costs change substantially over the days around the portfolio formation date.
} 
fundamental value is greater than (less than) the traded stock price. ${ }^{9}$ The relatively wide no-arbitrage bounds on the stock's bid and ask prices mean that the midpoint of the bounds will provide a noisy estimate of the stock's fundamental value and hence DOTS will be a noisy measure of stock mispricing. The noise in the DOTS measure will bias against finding a relation between DOTS and subsequent stock returns. The strong relation we document implies that the noise does not swamp the mispricing signal provided by DOTS.

Equations (1) and (2) show that the bounds provided by options are tighter when spreads are smaller. Thus, in order to reduce the noise in our estimate of DOTS for stock $i$ on date $t$, we place more weight on observations where the estimate of fundamental value is less noisy by taking a weighted-average across option pairs of all the DOTS $S_{i j t}$ estimates with weights given by the inverse of the sum of the spreads for each option pair, i.e., the inverse

$$
\begin{aligned}
& \text { of }\left(C_{a s k}^{i j t}-C_{b i d}^{i j t}\right)+\left(P_{a s k}^{i j t}-P_{b i d}^{i j t}\right), \\
& \qquad D O T S_{i t}=100 \sum_{j=1}^{J} \frac{\left(C_{a s k}^{i j t}-C_{b i d}^{i j t}+P_{a s k}^{i j t}-P_{b i d}^{i j t}\right)^{-1}}{\sum_{k=1}^{J}\left(C_{a s k}^{i k t}-C_{b i d}^{i k t}+P_{a s k}^{i k t}-P_{b i d}^{i k t}\right)^{-1}} \text { DOTS }_{i j t},
\end{aligned}
$$

where $J$ is the number of option pairs.

\footnotetext{
${ }^{9}$ Although the DOTS measure might reflect price pressure in the options market rather than in the stock market, any such effect will be limited. The ability to write additional option contracts makes for a highly elastic supply of options. Muravyev (2016) documents that, since option market-makers manage their inventory risk on a portfolio basis, it is option market-wide order imbalances that affect option prices rather than option-specific order imbalances. In the Gârleanu, Pedersen, and Poteshman (2009) model, options market demand/supply shocks have the same effect on the prices of puts and calls with the same strike and maturity. Since both $S^{L}$ and $S^{U}$ are unaffected by equal changes in the prices of calls and puts, our DOTS measure is unaffected by temporary buying/selling pressure in the options market. Christoffersen, Goyenko, Jacobs, and Karoui (2018) shows that options market-maker compensation for taking ongoing net long positions involves larger price discounts on more illiquid options. Again, our DOTS measure will be unaffected provided illiquidity-related price discounts are the same for puts and calls with the same strike and maturity.
} 


\section{Data and Characteristics of Portfolios Sorted on DOTS}

Price, quote, and volume data on stocks and options thereon is combined in order to analyze the characteristics of portfolios formed on the basis of DOTS.

\subsection{Data}

Daily and monthly stock prices, returns, trading volume, and numbers of shares outstanding (share codes 10 and 11) traded on the NYSE, NASDAQ, or AMEX (exchange codes 1, 2, and 3) are extracted from CRSP. ${ }^{10}$ We follow Gao and Ritter (2010) in adjusting reported volume data for stocks trading on NASDAQ before 2004. The stock data is merged with daily options data from OptionMetrics for the period between 1996 and 2013. We form pairs of call and put options with the same maturities and strike prices whenever both options satisfy the following restrictions: (i) their expiration date is at least one week but not more than one month away, (ii) their annualized implied volatility does not exceed 250\%, (iii) their bid prices are non-missing and strictly positive, (iv) their ask prices are non-missing and strictly greater than their bid prices, (v) their open interest is greater than zero, and (vi) their deltas are non-missing. We delete option pairs for which the difference between the call delta and the put delta falls outside the interval $[0.9,1.1]$. While not explicitly designed to do so, these option filters remove penny stocks (i.e., stocks with closing prices below $\$ 5$ (\$1) before (after) April 2001) from the final sample. For each stock-date, we also retain the 30-day at-the-money put and call implied volatilities from the OptionMetrics Volatility Surface data, similar to An et al. (2014). ${ }^{11}$

In order to compute the option-implied bounds from expressions (1) and (2), continuously compounded risk-free rates extracted from the OptionMetrics Zero Coupon Yield Curve

\footnotetext{
${ }^{10}$ If closing bid quotes are equal to or greater than closing ask quotes these quotes are set to missing.

${ }^{11}$ At-the-money is defined here as having an absolute delta equal to $50 \%$.
} 
dataset are used to calculate the present value of the strike price and the present value of dividends with ex-dates prior to the maturity of the options in each put-call pair. The present value of each dividend is calculated by discounting back from its payment date. ${ }^{12}$ We use the OptionMetrics Dividend dataset and define a firm to be a dividend payer when there is a distribution of type 1 (i.e., cash dividends) as this is most likely to affect the option-implied stock price bounds. ${ }^{13}$ Our final sample includes 5,566 distinct stocks with monthly cross-sections ranging from 751 (1996) to 1,781 (2007) observations

The time-series of risk factors from Ken French's website are used to compute riskadjusted returns using a five-factor model based on the market, size, value, robust-minusweak profitability and conservative-minus-aggressive investment factors (Fama and French (2015)). To relate our findings to microstructure effects, we obtain high frequency data on stock order flow imbalances from NYSE Trade and Quote (TAQ) data for the period 19962013. We obtain high frequency data on option order imbalances from Trade Alert LLC for the period April 2008-December 2013. Trade Alert LLC data contains all the messages recorded by the Options Price Reporting Authority (OPRA) feed. In order to focus on the combined effects of stock price pressure and informed options trading around information events, we collect quarterly earnings announcement data for the 1996-2013 period from $\mathrm{I} / \mathrm{B} / \mathrm{E} / \mathrm{S}$.

\footnotetext{
${ }^{12}$ We use the standardized set of maturities for risk-free rates in OptionMetrics and linearly interpolate for other maturities. We discount realized dividends at the risk-free rate. While van Binsbergen, Brandt, and Koijen (2012) show that the risk associated with dividends to be paid over a two-year horizon is priced, the dividends we consider are almost certain since they have almost always been announced and are payable within 22 calendar days of the date on which the high and low DOTS portfolios are formed. Our results are robust to excluding dividend-paying stocks altogether.

${ }^{13}$ We exclude from our final sample all stocks with a liquidating dividend (LIQUID_FLAG=1), a dividend cancellation (CANCEL_FLAG $=1$ ), a stock dividend, a stock split or a special dividend (DISTR_TYPE $=2$, 3 , or 5 , with AMOUNT $>0$ ) between the portfolio formation date and the option expiration date, as these events may give rise to adjustments in the terms of the option contracts.
} 


\subsection{Characteristics of portfolios sorted by DOTS}

Table 1 reports summary statistics of characteristics of the DOTS decile portfolios formed at month-end over the period 1996 through 2013. Appendix A provides complete definitions of all variables in Table 1.

[Table 1 about here]

Panel A of Table 1 shows that the average values of DOTS in the high and low DOTS deciles are $0.79 \%$ and $-0.92 \%$ respectively, indicating that transacted stock prices deviate substantially from option-implied values in these DOTS deciles. As shown in Panel B, stocks in the extreme deciles of DOTS have smaller market capitalizations, larger stock order imbalances, higher abnormal turnover, higher Amihud illiquidity measures, higher idiosyncratic volatility, and larger proportional bid-ask spreads. Regarding the larger spreads of the stocks in the extreme DOTS deciles, Comerton-Forde, Hendershott, Jones, Moulton, and Seasholes (2010) and Hendershott and Menkveld (2014) observe that spreads are high when market-maker inventory levels are also high, which happens when the specialist has absorbed a positive supply shock. Presumably this reflects a decrease in the bid price relative to the ask price as the specialist becomes less willing to acquire additional inventory. One would also expect the spread to be large when the specialist has accommodated a negative supply shock and holds less than an optimal inventory position, with the specialist raising the ask relative to the bid. If extreme DOTS values reflect temporary pressure in stock prices, then we expect to observe an increase in bid-ask spreads for stocks that enter the DOTS extreme portfolios on the formation date and the increase in bid-ask spreads should revert once the price pressure subsides. Figure 3 shows that this prediction is borne out. The characteristics of stocks in the extreme DOTS deciles are consistent with these stocks 
facing larger market frictions, higher illiquidity, greater potential mispricing and ultimately greater impediments to arbitrage forces.

\section{[Figure 3 about here]}

The characteristics of the options in the extreme DOTS deciles (reported in Table 1, Panel C) suggest that stocks in these portfolios could experience price pressure without the pressure being fully reflected in option prices. Bid-ask spreads on the call and put options are larger for the stocks in the extreme DOTS deciles and these wider spreads cause the spread between the option-implied lower and upper bound to be wider (above 3\%) for stocks in the extreme DOTS deciles. Wider option-implied price bounds imply a looser link between option and stock prices, which means that a large supply/demand shock in the stock market is less likely to trigger an update in option quotes or lead to an arbitrage opportunity. When a shock leads to stock price pressure, option-implied prices can provide an anchor for fundamental stock values that helps to distinguish stock price movements due to pressure versus news. Note also that trading activity in options written on the stocks in the extreme DOTS deciles is low: on average, the calls (puts) used to compute DOTS last traded 5 (9) calendar days before the formation date. ${ }^{14}$

Panel C shows that the average IVS increases monotonically across DOTS deciles. Similarly, monthly changes in IVS show a monotonic pattern across the deciles. The patterns are consistent with the correlations reported in Panel D. DOTS and the IVS measure used in Cremers and Weinbaum (2010) have a strong positive correlation of 0.95. Consistent with $\triangle I V S$ being a noisy measure of $I V S$ and hence of DOTS, the empirical correlation between DOTS and the monthly $\triangle I V S$ measure used in An et al. (2014) is 0.44.

\footnotetext{
${ }^{14}$ Recall that we only use the more liquid options in our calculation of DOTS.
} 


\subsubsection{Stock order imbalances $(S O I)$}

Panel B in Table 1 reports the average stock order imbalance $(S O I)$ for each decile portfolio formed on the basis of DOTS. For each stock-day, we compute the SOI as the difference between the dollar value of buyer-initiated and seller-initiated stock trades, divided by the sum of all trades. We define the Abnormal SOI as the difference between the SOI on that day and the average $S O I$ of that stock over the 30 trading days ending 11 trading days prior to the portfolio formation date. The data filters and computation techniques applied to TAQ data to obtain daily order imbalance measures are described in Chordia, Roll, and Subrahmanyam (2002) and Chordia and Subrahmanyam (2004) with the direction of each stock transaction (i.e., buyer- or seller-initiated) determined according to the Lee and Ready (1991) algorithm. The average Abnormal SOI decreases monotonically across DOTS decile portfolios. Stocks in the high DOTS decile experience the largest abnormal net selling $(-6.6 \%$ with a $t$-value of -16.7$)$, while stocks in the low DOTS decile exhibit the largest abnormal net buying (5.9\% with a $t$-value of 17.1$)$. This negative relation is consistent with high (low) DOTS stocks experiencing selling (buying) pressure. Panel D reports that the average of the cross-sectional correlations between DOTS and SOI estimated each month for the period 1996-2013 is -0.166 .

In addition, we also look at $S O I$ around the portfolio formation date. For the full sample and for the high and low DOTS deciles Figure 4(a) plots the equal-weighted average Abnormal SOI on each day of the 21-day window centered on the portfolio formation date. The large $S O I$ in the extreme DOTS deciles on the formation date quickly reverts to zero, consistent with temporary spikes in buying/selling associated with extreme values of DOTS. All indications are that the stocks in the extreme DOTS deciles are under pressure: they have the highest stock order imbalances and the highest bid-ask spreads.

[Figure 4 about here] 


\subsubsection{Option order imbalances $(O O I)$}

Panel $\mathrm{C}$ in Table 1 also reports the abnormal option order imbalance $(O O I)$ calculated from Trade Alert LLC intraday data on option trades over the period April 2008 to December 2013. For each option trade, the signed share-equivalent volume is calculated as the product of the delta of the option contract, a plus one (minus one) indicator function of whether the trade was initiated by the buyer (seller) of the option, and the number of contracts traded. Trade Alert classifies an option trade as buyer-initiated (seller-initiated) if the transaction price is above (below) the most recent midquote price. Following $\mathrm{Hu}$ (2014), we apply the Lee and Ready (1991) tick rule whenever the quote rule fails to classify a trade. The OOI for a stock on a given day is defined as the signed share-equivalent volume across all trades in options on the stock that day, normalized by the unsigned share-equivalent option volume that day. Consistent with how we measure Abnormal SOI, we compute the abnormal OOI as the difference between the $O O I$ of the stock on that day and the average $O O I$ over the 30 trading days ending 11 trading days prior to the portfolio formation date. As seen in Panel $\mathrm{C}$, the abnormal $O O I$ is decreasing across the DOTS deciles, indicating that there is in aggregate net buyer-initiated (seller-initiated) trading in calls and net seller-initiated (buyer-initiated) trading in puts for stocks in the low (high) DOTS decile. The time series average abnormal OOI of the low and high DOTS deciles are $2.9 \%$ and $-3.3 \%$ respectively, with $t$-values of 4.96 and -5.37 respectively. This pattern is inconsistent with option trading on negative (positive) information about stocks in the low (high) DOTS decile.

Figure 4(b) depicts the average abnormal $O O I$ on the days surrounding the month-end for stocks in the extreme deciles of DOTS. There are more buyer-initiated (seller-initiated) trades in call options and seller-initiated (buyer-initiated) trades in put options when the underlying stock's option-implied value is below (above) its traded price, i.e. when DOTS is low (high). In summary, the characteristics of the options in the extreme DOTS deciles do 
not support the contention that informed trading is concentrated in the options underlying these stocks.

\section{Stock Return Predictability Derived from Option Prices}

\subsection{Daily returns on portfolios sorted by DOTS, IVS and $\triangle I V S$}

Panel A of Table 2 reports the value-weighted excess returns for the high and low DOTS decile portfolios, as well as the difference between the two. Decile portfolios are formed based on DOTS on the last trading day of each month and held for one day after portfolio formation. The one-day return of the high DOTS minus low DOTS portfolio is large at 82 bps (Column (3)), consisting of 64 bps for the long leg and -18 bps for the short leg. The predictive ability of DOTS is similar to the predictability previously documented in the literature that uses transformations of DOTS. Specifically, high minus low decile portfolios formed on the basis of the IVS provide a one-day holding period return of $86 \mathrm{bps}$, as shown in Column (3) of Panel B. High minus low decile portfolios formed on the basis of the monthly $\Delta I V S$ as proposed in An et al. (2014), produce a one-day holding period return of 53 bps (Column (3) of Panel C). Hence, all three measures generate predictability in one-day stock returns. As expected, because the $\triangle I V S$ methodology produces a noisy measure of monthend information and price pressure effects, $\triangle I V S$ portfolios earn smaller returns than those formed on the basis of the DOTS or IVS approaches. ${ }^{15}$

\footnotetext{
${ }^{15}$ To rule out the possibility that our results are driven by the turn-of-the-month effect documented in Etula, Rinne, Suominen, and Vaittinen (2015), we perform the DOTS sorting on days ranging from eight trading days before to eight trading days after month-end. The returns are qualitatively unaffected. Over the other 16 formation days around month-end, the return on the value-weighted long-short portfolio ranges from $22 \mathrm{bps}$ to $56 \mathrm{bps}$ on the first day after portfolio formation (with $t$-stats ranging from 2.15 to 6.04 ).
} 
[Table 2 about here]

Table 2 also reports a strong relation between DOTS, IVS, or $\triangle I V S$ and past stock and option-implied returns. If selling (buying) pressure in the stock market is what creates a large positive (negative) DOTS, then it should be accompanied by a negative (positive) change in stock prices on the formation day. In contrast, the hypothesis of informed trading in options predicts that a large positive (negative) DOTS should be accompanied by a positive (negative) change in option-implied prices on the formation day. Panel A of Table 2 shows that, on the day on which DOTS is computed (i.e., day $t-1$ ), the portfolio that buys stocks in the high DOTS decile and shorts stocks in the low DOTS decile, exhibits a negative traded stock return of $-144 \mathrm{bps}$, and a negative option-implied return of -38 bps, both statistically significant. These returns are consistent with stock price pressure and inconsistent with informed trading in the options market. We find similar results for the $I V S$ and $\triangle I V S$ measures in Panels $\mathrm{B}$ and $\mathrm{C}$, respectively.

Figure 5 illustrates graphically the same reversal patterns as in Table 2. The high and low DOTS stocks display a clear reversal of the returns observed immediately prior to the sorting date. While traded stock returns appear to reverse, this is not evident for option-implied returns.

[Figure 5 about here]

For both low and high DOTS stocks, the average option-implied return on the formation day has the same sign as the traded return, but is of a much smaller magnitude. Over the formation day plus the first holding day, it is the case that cumulative traded stock returns are nearly identical to the cumulative option-implied returns for both the low and high DOTS decile portfolios. The reversal of the traded stock return on the high and low DOTS stocks between the sorting day and the following day constitutes an important piece of evidence 
that the return predictability identified by DOTS, IVS, and $\triangle I V S$ is to a large extent driven by price pressure in the stock market that is not reflected in option prices. Panel A reports that the value-weighted midquote return on the long-short portfolio on the first holding day is $22 \mathrm{bps}$, implying that the predictability based on DOTS is not fully explained by bid-ask bounce. The value-weighted overnight return from the close of the sorting day to the open of the next trading day accounts for 52 bps of the 82 bps close-to-close return, suggesting that much of the stock price pressure is reversed in the overnight returns.

In summary, the results in Table 1 and Table 2 provide several indicators that stocks in the high (low) DOTS decile are under selling (buying) pressure in the stock market. First, stocks in the extreme DOTS deciles are more illiquid and experience high trading activity. Second, high DOTS decile stocks experience abnormally large net sell orders during the formation period, while stocks in the low DOTS decile have abnormally large net buy orders. Third, order imbalances in the options market on the formation day are more consistent with option price-based predictability being driven by stock price pressure than by informed trading in options markets.

\subsection{Zero option volume subsample analysis}

If informed trading in options drives the ability of DOTS, IVS, and $\triangle I V S$, to predict future stock returns, then we should observe no predictability in a sample of stocks restricted to those with zero trading in options. Across the three Panels of Table 2, Column (6) reports that the predictability of $D O T S, I V S$, and $\triangle I V S$ is virtually unchanged when we restrict our sample to the subset of stocks with zero trading in options on the formation day. The zero-volume restriction applies to options across all maturities and strikes on that stock, 
not just the short-maturity options used to construct the sorting measures. This is strong evidence supportive of the price pressure hypothesis. ${ }^{16}$

In unreported results, we find the predictability is unchanged when we restrict the sample to the set of stocks having both zero option volume and zero change in option-implied prices on the formation day. The latter finding suggests that the stock return predictability is unchanged when there is literally no action in the options market, contrary to the informed trading hypothesis. We can think of the option-implied value as an anchoring point for true value when no value-relevant information is arriving and no options are being traded. To the extent that liquidity-based trades do shift the traded stock price up or down, DOTS captures the temporary pricing distortion and predicts the subsequent reversal at the cessation of the stock price pressure.

\subsection{Daily returns on bivariate portfolios formed based on DOTS and a composite proxy for stock price pressure}

If option price-based stock return predictability were mostly explained by price pressure, then the predictive role of DOTS should significantly diminish when we control for the effect of stock price pressure. Cremers and Weinbaum (2010) use lagged stock returns as a control for price pressure in their analyses. However, stock returns can also reflect new information and are therefore a noisy proxy for price pressure. To better control for price pressure, we create a composite price pressure $(C P P)$ proxy for each stock on the formation day. $C P P$ is based on three measures: stock return in excess of the market return, Abnormal SOI, and signed truncated abnormal stock turnover (Abnormal TURN). Abnormal TURN is defined as the deviation of stock turnover on the formation day from the average turnover

\footnotetext{
${ }^{16}$ It is unlikely that limit orders can both incorporate private information and clear the market without trade. OptionMetrics records the final quotes issued within the last 30 minutes of trading in their daily options market snapshot. Stale quotes for options that did not trade should lead to a decrease in the ability to identify stock return predictability arising from an informational superiority of options markets.
} 
during a benchmark window of 30 trading days ending 11 trading days before portfolio formation. Since price pressure is related to positive abnormal turnover, we truncate the abnormal turnover at zero whenever the deviation is negative. We then sign the truncated abnormal turnover by the sign of the formation-day stock return to indicate extreme buy or sell pressure. Large positive (negative) formation day stock returns, large positive (negative) Abnormal SOI, and large positive (negative) signed truncated Abnormal TURN, all indicate high buy (sell) pressure in the stock. By combining the three measures, we reduce the noise in each measure and capture the common price pressure. ${ }^{17}$

The CPP proxy is constructed as follows. For each of the three price pressure measures, we rank the stocks at the end of each month, with the highest (lowest) rank indicating extreme buy (sell) pressure. Stocks are assigned ranks from 1 to 100 corresponding to the stock's percentile ranking. A stock's composite rank, $C P P$, is the equal-weighted average of its rank across the three measures.

To examine option-based stock return predictability after controlling for price pressure, stocks are sorted at each month-end based on the $C P P$ proxy and grouped into quintiles. Within each CPP quintile, stocks are then grouped into DOTS quintiles. The sequential sorting yields twenty-five portfolios whose value-weighed returns are calculated on the trading day immediately after the formation day. Table 3 reports the time-series average daily portfolio returns in excess of the market return. The sample size is reduced from 297,276 to 161,100 as we require the stocks to have valid observations of $C P P$ which restricts the sample to NYSE stocks only. As shown in Panel A of Table 3, the high DOTS minus low DOTS quintile portfolio generates significant excess returns of 38 bps. In Panel B, we report the excess returns on the 25 double-sorted portfolios. Here, we find stronger evidence of DOTS predicting stock returns when accompanied by extreme selling or buying pressure.

\footnotetext{
${ }^{17}$ We get similar results if we use (signed) stock turnover on the formation day directly instead of abnormal turnover.
} 
For instance, the high minus low DOTS quintiles earn significant daily returns of around 40 bps when the stocks are under extreme price pressure. On the other hand, for stocks in the middle quintile of $C P P$, the high minus low DOTS portfolio earns less than one-half of these returns at 17 bps. Moreover, the larger reversals on stocks with high price pressure come from extreme DOTS stocks, supporting our contention that DOTS is strongly related to stock price pressure. Overall, the evidence indicates that more than one-half of the predictability due to DOTS can be attributed to price pressure in the stock market.

[Table 3 about here]

\subsection{Weekly and monthly returns for portfolios sorted by DOTS, $I V S$, and $\Delta I V S$}

Table 4 reports the returns to the DOTS, IVS, and $\triangle I V S$ decile portfolios over holding periods of one week and one month after portfolio formation, reflecting the holding periods in Cremers and Weinbaum and An et al.. ${ }^{18}$ The table reports value-weighted returns using the Fama and French (2015) five-factor model.

For holding periods of one week and one month, the predicted returns using DOTS as a sorting variable are $81 \mathrm{bps}$ and $96 \mathrm{bps}$, respectively (see Panel A). If we use the IVS measure (Panel B), we obtain 99 bps for one week and 148 bps for one month holding periods. If we use the monthly $\triangle I V S$ measure (Panel C), the returns are 61 bps for one week and 83 bps for one month. Hence, we obtain similar large return predictability, both statistically and economically, using any of the three measures.

\footnotetext{
${ }^{18}$ For stocks that delist during the month after the formation date, we determine the delisting date return from the delisting month return and the cumulative return over the prior days of the month. If there is no valid delisting return, we set the delisting month return equal to zero for delisting codes 100 to 399 . Following Shumway (1997), for delisting codes 500, 520, 551-574, 580, 584 we assign a delisting month return of $-30 \%$ and for other delisting codes, we assign a delisting month return of $-100 \%$. If the monthly return of a stock is not missing, then any missing daily stock returns during that month are set to zero.
} 
One interesting observation in Table 4 is that the returns on the first day are relatively large compared to the results for one week and one month. If it is the case that the firstday return accounts for most of the weekly and monthly returns, then this supports the hypothesis that price pressure in the stock market is an important driver of the observed predictability. Skipping a day between the formation and the holding periods substantially weakens the predictability across all three measures. For example, for DOTS, the predicted returns decrease to 2 bps for one week, and 22 bps for one month, and both values are not statistically different from zero (Panel A, Table 4). ${ }^{19}$

To investigate the persistence through time in the predictability in stock returns over both short and long horizons, we split our sample into two sub-periods: 1996 to 2005 and 2006 to 2013. The later period effectively represents an out-of-sample test of the Cremers and Weinbaum analysis which focused on the 1996-2005 sub-period. Table 4 shows that all predictability of weekly and monthly returns is concentrated in the first sub-period. In the more recent 2006 through 2013 subperiod, none of the three measures DOTS, IVS, or $\Delta I V S$, predicts weekly or monthly returns and all predictability is limited to the first day after portfolio formation.

[Table 4 about here]

\subsection{Predictability of stock returns based on DOTS and short-term reversals}

The underlying notion that DOTS captures temporary deviations of stock prices from fundamental values, followed by subsequent reversal of stock prices, is potentially related to the well-document literature on short-term stock return reversals in Jegadeesh (1990) and

\footnotetext{
${ }^{19}$ The effect of skipping a day on predictability is similar to that in Jegadeesh (1990) which documents that the abnormal monthly return to a contrarian strategy based on lagged monthly returns is 28.1 percent lower when the lagged monthly return is calculated excluding the last trading day of the month.
} 
others. For example, Avramov et al. (2006) and Nagel (2012) document strong evidence of return reversals at daily and weekly horizons linked to stock illiquidity. These studies also show that the return reversals weaken when a day is skipped between formation and holding periods or when returns are computed using bid-ask average prices, similar to the findings we report for predictability based on DOTS. Moreover, Hameed and Mian (2015) show that stock returns revert more when accompanied by larger stock order imbalances. The overlap in findings based on DOTS and short-term reversals supports the price pressure hypothesis emanating from frictions in the stock market.

Since a large part of the stock return predictability based on DOTS is not coming from trading in the options market, we explore the question of how well short-term reversals can explain such predictability. We do this by matching the stocks in the high and low DOTS deciles with stocks that are not in these extreme DOTS deciles (the stocks need not have traded options) but which have similar stock returns on the formation date. Specifically, for each stock in the extreme DOTS decile on each formation day, we select the matching stock that has the smallest difference in the formation day stock returns, while imposing a constraint that the return difference does not exceed $1 \mathrm{bp}$. This matching process reduces the sample size by $22 \%$ compared to Table 2 . As shown in Table 5 , by construction, the average daily returns of stocks in the extreme DOTS deciles and stocks in the matched sample are identical on the formation day. Interestingly, we find that the returns on these two samples are markedly different on the following day. The high DOTS minus low DOTS return difference is a significant $0.94 \%$, consistent with the results in Table $2 .{ }^{20}$ On the contrary, the matched sample does not generate predictable returns. Hence, the results in Table 5 confirm that the predictability based on DOTS is different from predictability arising from short-term stock return reversals. The cumulative evidence in Section 5 suggests that stock return predictability derived from option prices is a reflection of stock price pressure.

\footnotetext{
${ }^{20}$ The difference in returns with Table 2 stems from a smaller sample due to the matching restriction.
} 
[Table 5 about here]

\section{Simultaneous Effects of Stock Price Pressure and In- formed Options Trading on DOTS}

We turn now to two investigations of the simultaneous effect on DOTS of stock price pressure and information differences between markets. We develop and test a model which builds on the implication of Figure 1 that the two separate effects can be investigated by ana-

lyzing the difference between option-implied and traded stock returns immediately preceding the observation of DOTS. We conclude that unless more than $35 \%$ of the price pressure in the stock market is transferred to option-implied valuations, price pressure contributes more to the return predictability associated with DOTS on average than does the informational advantage of the options market. Second, a separate analysis of returns around corporate earnings announcements allows us to demonstrate the importance of stock price pressure in explaining option price-based predictability even at times when information-based option trading is likely to occur.

\subsection{A parsimonious model with stock price pressure and informed options trading}

To motivate the model, recall from Table 2 that on the formation date, DOTS is negatively related to both traded stock returns and option-implied returns. The latter result is consistent with option quotes being revised in the direction of stock price pressure and is contrary to option traders receiving positive (negative) private information if the stock's DOTS status is high (low). The partial transmission of stock price pressure to option quotes will occur when option market-makers condition their quotes on the stock price. Such conditioning 
will be optimal for option market-makers who lack the complete set of information available to traders in the stock market. The option-implied value of stock $i$ on any date $t$, denoted by $V_{i, t}^{O I}$, can differ from the stock's fundamental value, if price pressure in traded stock prices affects the option market-maker quotes. The weight that a rational option market-maker will put on the traded stock price in forming her estimate of fundamental value will be less than one and hence the option-implied stock value will reflect only a fraction of the pressure in the stock price. Let $\delta$ denote that fraction.

In general, traded and option-implied returns will reflect (i) information common to participants in both the options and stock markets, (ii) information unique to traders in the options market, and (iii) stock price pressure that may be only partially reflected in option prices. ${ }^{21}$ Assume that on date $t-2$ there are no price pressure or information differences between the two markets. Hence $V_{i, t-2}^{O I}=S_{i, t-2}$, where $S_{i, t-2}$ is the price of stock $i$ on date $t-2$. On date $t-1$ stock price pressure and/or information differences can lead to a divergence between the stock's traded price and its option-implied value. Stock $i$ 's option-implied value on date $t-1$ is given by:

$$
V_{i, t-1}^{O I}=S_{i, t-2}+\Delta_{i, t-1}^{\text {common }}+\Delta_{i, t-1}^{\text {special }}+\delta \mathrm{pp}_{i, t-1}
$$

where $\Delta_{i, t-1}^{\text {common }}$ denotes the dollar change in stock $i$ 's value between dates $t-2$ and $t-1$ due to the arrival of information common to stock and option traders (common information), $\Delta_{i, t-1}^{\text {special }}$ refers to information known only to option traders (special information), and $\mathrm{pp}_{i, t-1}$ denotes the dollar price pressure of stock $i$ on date $t-1$.

\footnotetext{
${ }^{21}$ Even for stocks in extreme DOTS deciles, common information is likely still the most important contributor to stock returns. The correlation between traded and option-implied returns on the formation day exceeds $90 \%$. For stocks in the center deciles of the DOTS distribution that number rises to $97 \%$.
} 
The traded stock price on date $t-1$ will reflect the common information that has arrived since $t-2$ as well as the stock price pressure on date $t-1$.

$$
S_{i, t-1}=S_{i, t-2}+\Delta_{i, t-1}^{c o m m o n}+\mathrm{pp}_{i, t-1}
$$

The traded stock return from $t-2$ to $t-1, r_{i, t-1}^{T}$, is

$$
r_{i, t-1}^{T}=\frac{\Delta_{i, t-1}^{\text {common }}+\mathrm{pp}_{i, t-1}}{S_{i, t-2}} .
$$

The option-implied return, $r_{i, t-1}^{O I}$, is

$$
r_{i, t-1}^{O I}=\frac{\Delta_{i, t-1}^{\text {common }}+\Delta_{i, t-1}^{\text {special }}+\delta \mathrm{pp}_{i, t-1}}{S_{i, t-2}}
$$

and the date $t-1$ difference between the option-implied and traded return is

$$
r_{i, t-1}^{O I}-r_{i, t-1}^{T}=\frac{\Delta_{i, t-1}^{\text {special }}-(1-\delta) \mathrm{pp}_{i, t-1}}{S_{i, t-2}}
$$

This difference will reflect both special information and that portion of the stock price pressure that is not reflected in option quotes. The relative importance of the two determinants of the difference can be empirically investigated using the following regression model:

$$
r_{i, t-1}^{T}=\beta_{0}+\beta_{1}\left(r_{i, t-1}^{O I}-r_{i, t-1}^{T}\right)+\epsilon_{i, t-1}
$$


Assuming that traders rationally revise their beliefs when new information arrives and that information arrival is independent of price pressure, the sensitivity of the traded return to the contemporaneous difference between the option-implied and traded return is given by

$$
\beta_{1}=-\frac{(1-\delta) \sigma^{2}\left(\frac{\mathrm{pp}_{i, t-1}}{S_{i, t-2}}\right)}{\sigma^{2}\left(\frac{\Delta_{i, t-1}^{\text {special }}}{S_{i, t-2}}\right)+(1-\delta)^{2} \sigma^{2}\left(\frac{\mathrm{pp}_{i, t-1}}{S_{i, t-2}}\right)} .
$$

Equation (6) shows that $\beta_{1}$ is zero when price pressure affects stock prices and optionimplied values equally; i.e., when $\delta$ is one. In this event, differences between option-implied and traded returns are due entirely to information reflected in option prices but not reflected in stock prices. Therefore, a necessary condition for a nonzero coefficient is the presence of price pressure in the stock market that is not fully reflected in option quotes; i.e., that $\sigma^{2}\left(\mathrm{pp}_{i, t-1} / S_{i, t-2}\right)>0$ and $\delta<1$. Using the full sample of 297,276 observations of traded and option-implied returns on the last trading day of the month, the time-series average of the monthly cross-sectional regression estimates of $\beta_{1}$ is significantly negative, with a point estimate equal to -0.765 , a standard error of 0.018 and a $t$-statistic of -42 . Thus, we can conclude that $(1-\delta) \sigma^{2}\left(\mathrm{pp}_{i, t-1} / S_{i, t-2}\right)>0$ and that stock price pressure not reflected in option prices is an important determinant of DOTS.

Equation (6) also shows that when price pressure in the stock market is not fully mirrored in option-implied values and there is no special information, then $\beta_{1}=1 /(1-$ $\delta) \leq-1$. Rather than being less than -1 , our $\beta_{1}$ estimate of -0.765 is significantly greater than -1 with an associated $t$-statistic of 13 . The twin inequalities $\beta_{1}>-1$ and $(1-\delta) \sigma^{2}\left(\mathrm{pp}_{i, t-1} / S_{i, t-2}\right)>0$ imply that the term $\sigma^{2}\left(\Delta_{i, t-1}^{\text {special }} / S_{i, t-2}\right)$ in the denominator of (6) must be positive. This analysis allows us to conclude not only that stock price pressure 
is one determinant of DOTS, but also that information reflected in option quotes and not in traded stock prices is a second determinant of DOTS.

What can our analysis tell us about the relative influence on DOTS of differential price pressure between the stock and options markets versus differences in information between the two markets? If price pressure is confined to the stock market (i.e., $\delta=0$ ), then $\beta_{1}$ provides an immediate estimate of the variability of traded stock returns due to price pressure relative to the variability of option-implied returns due to special information. The estimated value of -0.765 for $\beta_{1}$ implies that the relative importance of the two potential determinants of DOTS is

$$
\frac{\sigma^{2}\left(\frac{\mathrm{pp}_{i, t-1}}{S_{i, t-2}}\right)}{\sigma^{2}\left(\frac{\Delta_{i, t-1}^{\text {special }}}{S_{i, t-2}}\right)}=3.26
$$

Thus, if stock price pressure does not influence option quotes, our $\beta_{1}$ estimate implies that the variability of traded prices due to price pressure is 3.26 times as large as the variability of option-implied values due to special information. Further, given our estimate of $\beta_{1}$ of -0.765 , any value for $\delta$ less than 0.35 implies that the differential stock price pressure contributes more to the variability in DOTS than does the informational advantage of the options market. In summary, our analysis suggests that DOTS reflects both informed trading in the options market and price pressure in the stock market that is not reflected in option quotes. Importantly, unless stock price pressure has a significant influence on option quotes, stock price pressure is the primary driver of the predictability of stock returns in a broad sample of data that does not condition on the existence of an information event. In the next subsection we focus on specific information events. 


\subsection{Stock price pressure and informed options trading around in- formation events}

There can be a return to gathering private information about forthcoming earnings announcements (e.g., Amin and Lee (1997) and Roll et al. (2010) report that option trading around earnings announcements predicts stock returns). At the same time, earnings announcements are likely to increase the inventory and information asymmetry risks faced by market-makers who may respond by decreasing the depth of their quotes; i.e., stock price pressure associated with abnormal volume may be higher around earnings announcements (e.g. (So and Wang, 2014)).

To focus on option price-based return predictability around information events we merge I/B/E/S data with our options data to create a sample based around 68,945 quarterly earnings announcements. Portfolios are formed on the basis of the DOTS measure on the day preceding the earnings announcement. The announcement return is measured over days $[t, t+1]$ where day $t$ is the earnings announcement day. We also investigate return predictability immediately after the announcement by examining returns over the $[t+2, t+5]$ window. Each quarter, stocks are ranked on the basis of DOTS and decile portfolios are formed. The time-series average of the mean number of stocks in each decile is 95 .

Table 6 shows that the average value of DOTS on day $t-1$ is a strong predictor of

the announcement return over the $[t, t+1]$ period that captures the announcement. The cumulative traded return of a strategy long in a value-weighted portfolio of stocks in the high DOTS decile and short in a value-weighted portfolio of stocks in the low DOTS decile is 115 bps. As discussed in Section 6.1, one way to distinguish the stock price pressure and informed options trading explanations of the stock return predictability associated with DOTS is via an examination of traded and option-implied returns preceding the observation of DOTS. The strategy's positive announcement return is preceded by a strong negative traded return 
of -157 bps on the day prior to the announcement date. The stock return predictability associated with DOTS vanishes beyond the first day after the earnings announcement, i.e., over the $[t+2, t+5]$ window. This result is consistent with price pressure being a significant component of the stock return predictability of option prices even around information events. The return reversal around earnings announcements is analogous to that documented as occurring more generally at month-end in Table 2. The reversal is also consistent with the strong return reversals around earnings announcements documented in So and Wang (2014).

[Table 6 about here]

The long-short portfolio exhibits a negative option-implied return of -55 bps on day $t-1$ which is consistent with stock price pressure being partly reflected in option prices. The significant negative option-implied return on day $t-1$ is not consistent with the predictability associated with DOTS being entirely due to information reflected in option prices before stock prices. The day $t-1$ difference between the option-implied and traded returns on the long-short portfolio is a significantly positive $102 \mathrm{bps}$. Consistent with price pressure and information differences both being short-lived, the model in Section 6.1 implies that this difference should revert quickly. Indeed, we observe a full reversion from the formation day to the announcement period: the difference between option-implied and traded returns on the long-short portfolio switches from +102 bps on $t-1$ to -112 bps over $[t, t+1]$.

\section{Conclusion}

The deviation of traded stock prices from option-implied stock values may arise from informed trading in options and/or supply/demand shocks in the stock market. In the event that stocks are under downward (upward) price pressure or there is trading on positive (negative) information in the options market, the traded stock price will be below (above) 
the option-implied value and will be expected to rise (fall) in the future. Moreover, this stock price correction is expected to occur rapidly as the stock price pressure subsides and options market information spills over to the stock market. We show that the various optionbased predictors of stock returns commonly used as metrics of informed trading, such as the implied volatility spreads and changes therein, are transforms of the difference between the option-implied value and the traded price of a stock, i.e., transforms of DOTS.

We demonstrate that the option-based predictability is primarily driven by price pressure in the stock market. First, we find that stocks in the extreme deciles of DOTS have characteristics that reflect low liquidity, namely, smaller market capitalizations, larger stock bid-ask spreads, higher idiosyncratic volatility and higher Amihud illiquidity. Second, we find that the predictability based on DOTS is positively related to stock price pressure proxied by a combination of stock returns, abnormal stock order imbalances, and stock trading volume. The one-day returns on long-short portfolios formed on the basis of DOTS more than doubles when the stocks are under price pressure during the formation period. Third, the portfolio returns reduce substantially when stock returns are computed based on bidask average prices instead of traded prices. Fourth, when the long-short portfolio is held for longer periods of one week or one-month, its returns are relatively small on days subsequent to the first day after portfolio formation. Fifth, DOTS-based predictability does not seem related to trading activity in the options market, which is not the relation that would be expected if informed trading in the options market were the sole explanation of the cross-market predictability. Sixth, the predictability of DOTS is not simply a reflection of reversals of recent past returns. Our evidence implies that option-implied stock prices help distinguish price changes coming from stock price pressure from those due to news and that stock price pressure is an importance source of option price-based predictability of stock returns. 


\section{References}

Amihud, Y. 2002. Illiquidity and stock returns: Cross-section and time-series effects. Journal of Financial Markets 5:31-56.

Amin, K. I., and C. M. C. Lee. 1997. Option Trading, Price Discovery, and Earnings News Dissemination. Contemporary Accounting Research 14:153-192.

An, B.-J., A. Ang, T. G. Bali, and N. Cakici. 2014. The joint cross section of stocks and options. Journal of Finance 69:2279-2337.

Atilgan, Y. 2014. Volatility spreads and earnings announcement returns. Journal of Banking and Finance 38:205-215.

Avramov, D., T. Chordia, and A. Goyal. 2006. Liquidity and Autocorrelations in Individual Stock Returns. Journal of Finance 61:2365-2394.

Bali, T. G., and A. Hovakimian. 2009. Volatility spreads and expected stock returns. Management Science 55:1797-1812.

Chordia, T., R. Roll, and A. Subrahmanyam. 2002. Order imbalance, liquidity, and market returns. Journal of Financial Economics 65:111-130.

Chordia, T., and A. Subrahmanyam. 2004. Order imbalance and individual stock returns: Theory and evidence. Journal of Financial Economics 72:485-518.

Chordia, T., A. Subrahmanyam, and Q. Tong. 2014. Have capital market anomalies attenuated in the recent era of high liquidity and trading activity? Journal of Accounting and Economics 58:41-58.

Christoffersen, P., R. Goyenko, K. Jacobs, and M. Karoui. 2018. Illiquidity premia in the equity options market. Review of Financial Studies 31:811-851. 
Comerton-Forde, C., T. Hendershott, C. M. Jones, P. C. Moulton, and M. S. Seasholes. 2010. Time variation in liquidity: the role of market-maker inventories and revenues. Journal of Finance 65:295-331.

Cox, J. C., and M. Rubinstein. 1985. Options markets. Prentice Hall.

Cremers, M., and D. Weinbaum. 2010. Deviations from put-call parity and stock returns. Journal of Financial and Quantitative Analysis 45:335-367.

Easley, D., M. O'Hara, and P. S. Srinivas. 1998. Option volume and stock prices: Evidence on where informed traders trade. Journal of Finance 53:431-465.

Etula, E., K. Rinne, M. Suominen, and L. Vaittinen. 2015. Dash for cash: Month-end liquidity needs and the predictability of stock returns. Working Paper.

Fama, E. F., and K. R. French. 2015. A five-factor asset pricing model. Journal of Financial Economics 116:1-22.

Gao, X., and J. R. Ritter. 2010. The marketing of seasoned equity offerings. Journal of Financial Economics 97:33-52.

Gârleanu, N., L. H. Pedersen, and A. M. Poteshman. 2009. Demand-based option pricing. Review of Financial Studies 22:4259-4299.

Hameed, A., and G. M. Mian. 2015. Industries and Stock Return Reversals. Journal of Financial and Quantitative Analysis 50:89-117.

Hendershott, T., and A. J. Menkveld. 2014. Price pressures. Journal of Financial Economics 114:405-423.

Hu, J. 2014. Does option trading convey stock price information? Journal of Financial Economics 111:625-645. 
Jegadeesh, N. 1990. Evidence of predictable behavior of security returns. Journal of Finance 45:881-898.

Johnson, T. L., and E. C. So. 2012. The option to stock volume ratio and future returns. Journal of Financial Economics 106:262-286.

Lee, C. M. C., and M. J. Ready. 1991. Inferring trade direction from intraday data. Journal of Finance 46:733-746.

Manaster, S., and R. J. Rendleman. 1982. Option prices as predictors of equilibrium stockprices. Journal of Finance 37:1043-1057.

Muravyev, D. 2016. Order flow and expected option returns. Journal of Finance 71:673-708.

Muravyev, D., N. D. Pearson, and J. P. Broussard. 2013. Is there price discovery in equity options? Journal of Financial Economics 107:259-283.

Nagel, S. 2012. Evaporating liquidity. Review of Financial Studies 25:2005-2039.

Newey, W., and K. D. West. 1987. A simple, positive semi-definite, heteroskedasticity and autocorrelation consistent covariance matrix. Econometrica 55:703-708.

Roll, R. R., E. S. Schwartz, and A. Subrahmanyam. 2010. O/S: The relative trading activity in options and stock. Journal of Financial Economics 96:1-17.

Shang, D. 2016. Option markets and stock return predictability. University of Arizona PhD Dissertation.

Shumway, T. 1997. The delisting bias in CRSP data. Journal of Finance 52:327-340.

So, E. C., and S. Wang. 2014. News-driven return reversals: Liquidity provision ahead of earnings announcements. Journal of Financial Economics 114:20-35. 
van Binsbergen, J., M. W. Brandt, and R. S. J. Koijen. 2012. On the timing and pricing of dividends. American Economic Review 102:1596-1618.

Xing, Y., X. Zhang, and R. Zhao. 2010. What does the individual option volatility smirk tell us about future equity returns? Journal of Financial and Quantitative Analysis 45:641662.

Yan, S. 2011. Jump risk, stock returns, and slope of implied volatility smile. Journal of Financial Economics 99:216-233. 

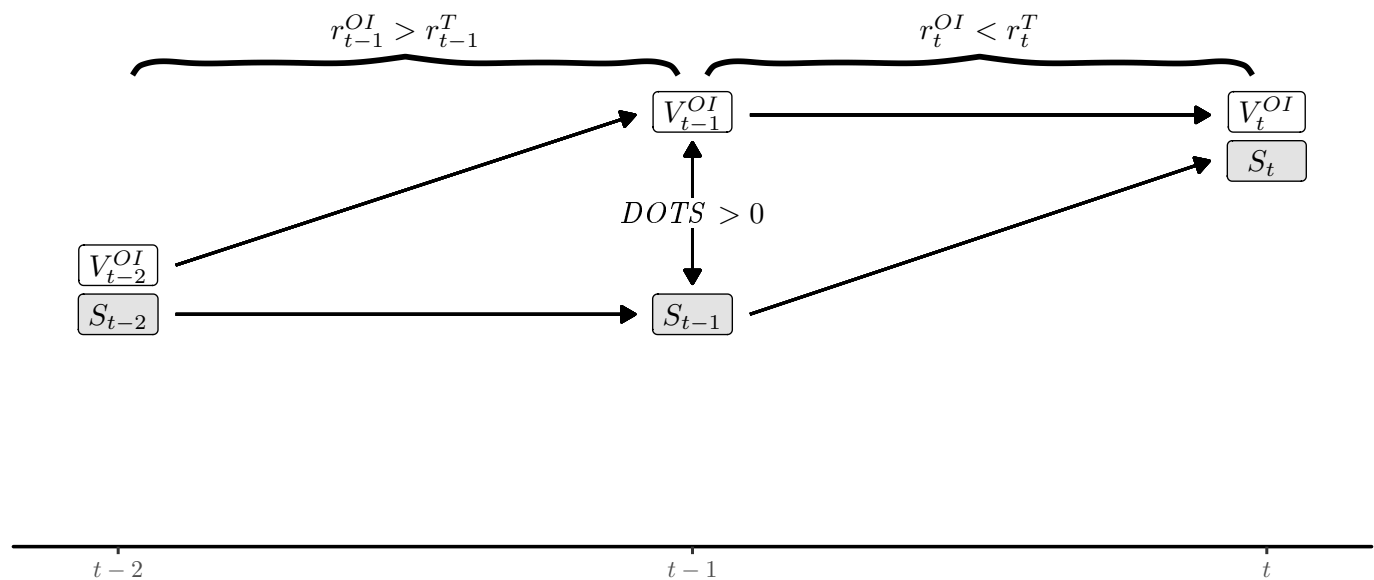

(a) Informed trading in options

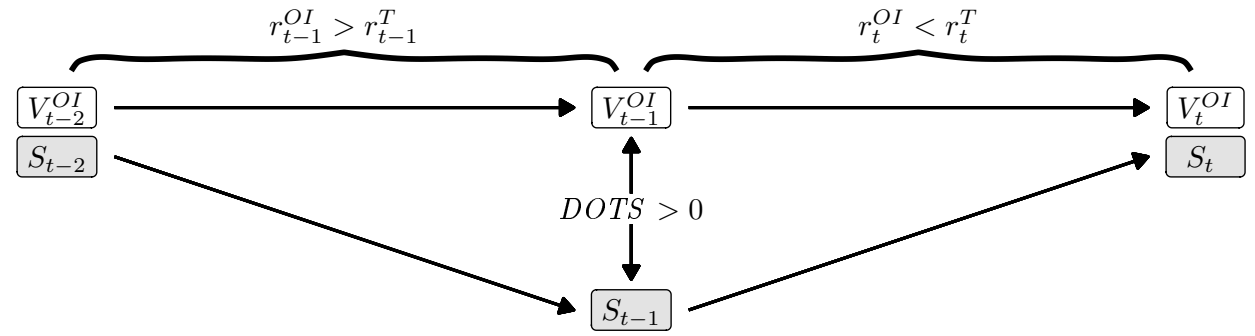

$t-2$

$t-1$

(b) Price pressure in stocks

Figure 1: A positive DOTS value and its relation to informed trading in options versus price pressure in stocks

This figure illustrates how a positive difference between option-implied stock value and traded stock price (a positive value for $D O T S$ ) can reflect either differential information between the stock and options markets, or price pressure in the stock market. $S_{t}$ denotes the traded stock price on day $t, V_{t}^{O I}$ denotes the optionimplied stock value on day $t, r_{t}^{O I}$ is the option-implied stock return from the close on day $t-1$ to the close on day $t$, and $r_{t}^{T}$ is the traded stock return from the close on from day $t-1$ to the close on day $t$. DOTS is observed on day $t-1$. 


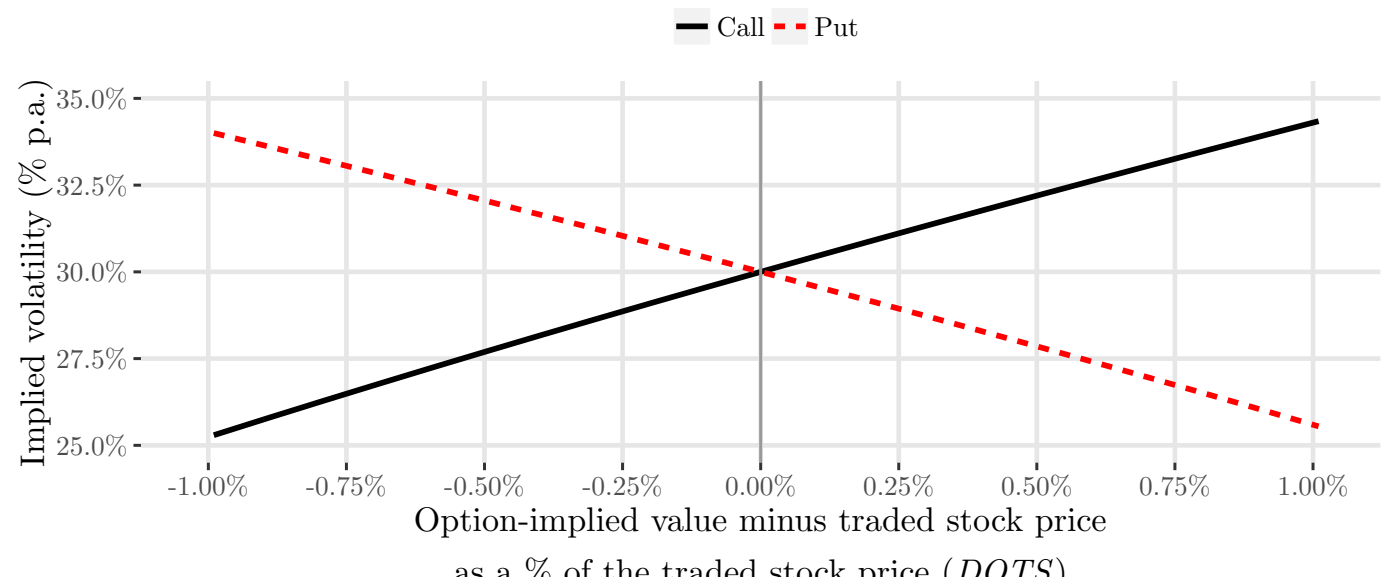

as a $\%$ of the traded stock price $(D O T S)$

\section{Figure 2: At-the-money call and put implied volatilities}

This figure plots the Black-Scholes implied volatilities of a call and a put option as a function of the difference between the option-implied value and the traded stock price as a $\%$ of the traded stock price (i.e., as a function of DOTS). The options have a strike price equal to the stock's fundamental value and a maturity of 1 month. The risk-free interest rate and the stock return volatility per annum are $0 \%$ and $30 \%$, respectively. The dollar option prices are computed by Black-Scholes using the stock's option-implied value as an input. The implied volatilities are computed from Black-Scholes using the traded stock price as the input. 


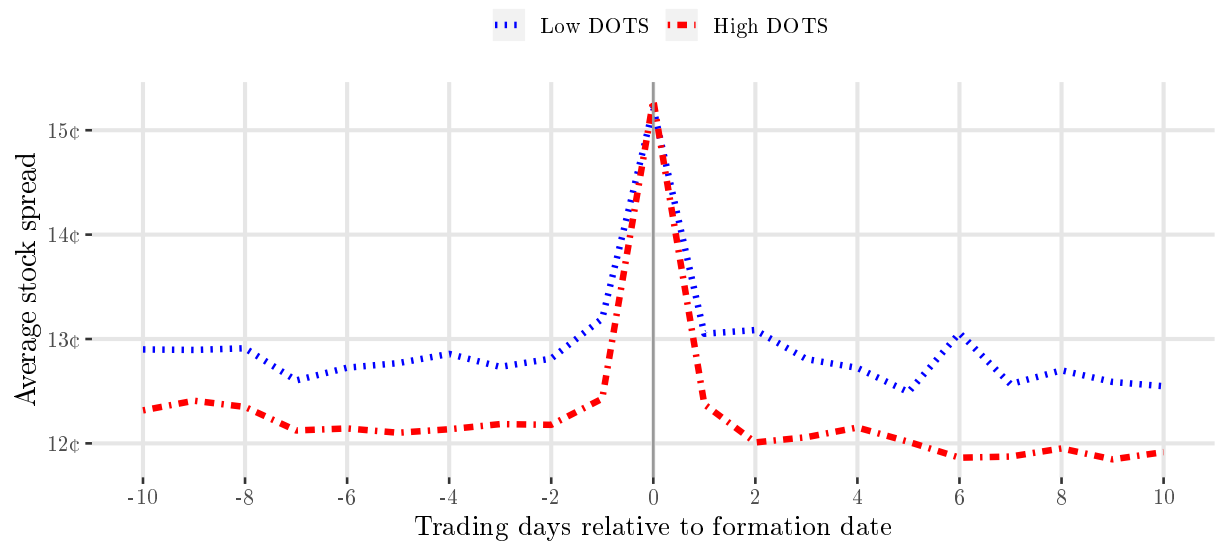

(a) Average bid-ask spreads ( $\phi)$

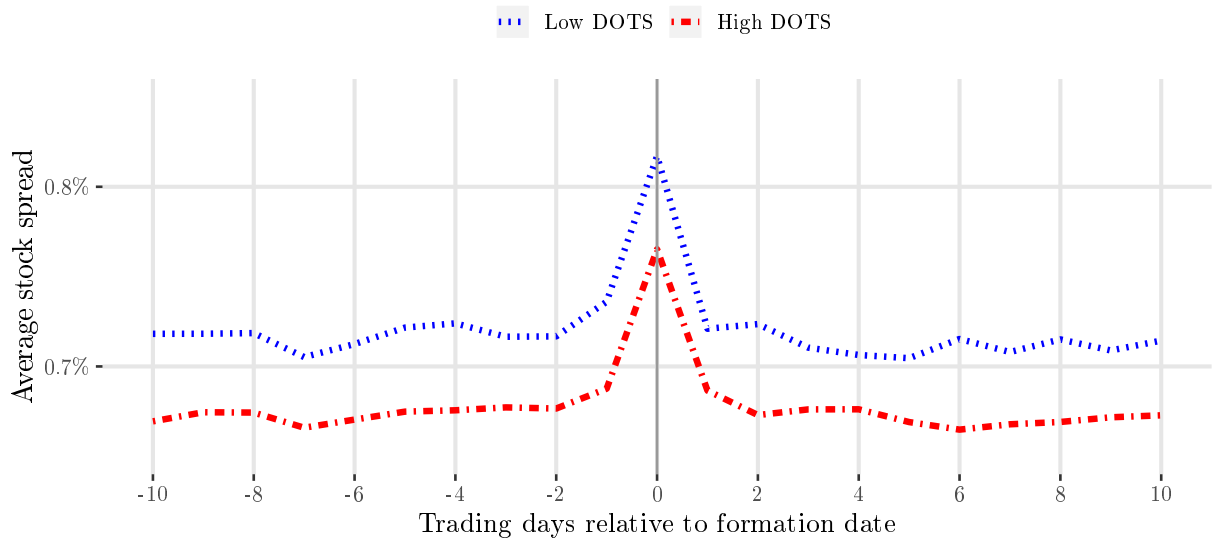

(b) Average bid-ask spreads (\%)

\section{Figure 3: Stock bid-ask spreads around the DOTS portfolio formation date}

The top panel plots the average closing bid-ask spread in cents from ten trading days prior to the formation date until ten trading days after the formation date. The bottom panel plots the average closing bid-ask spread relative to the midpoint of the closing bid and ask quotes in percentage terms. The dash-dotted line corresponds to the portfolio of stocks in the highest DOTS decile, and the dotted line corresponds to the stocks in the lowest DOTS decile. The average is computed in the cross-section first, and then averaged across time. Stocks are sorted into deciles by DOTS on the last trading day of the month (day zero). The sample covers the period between January 1996 and December 2013. 


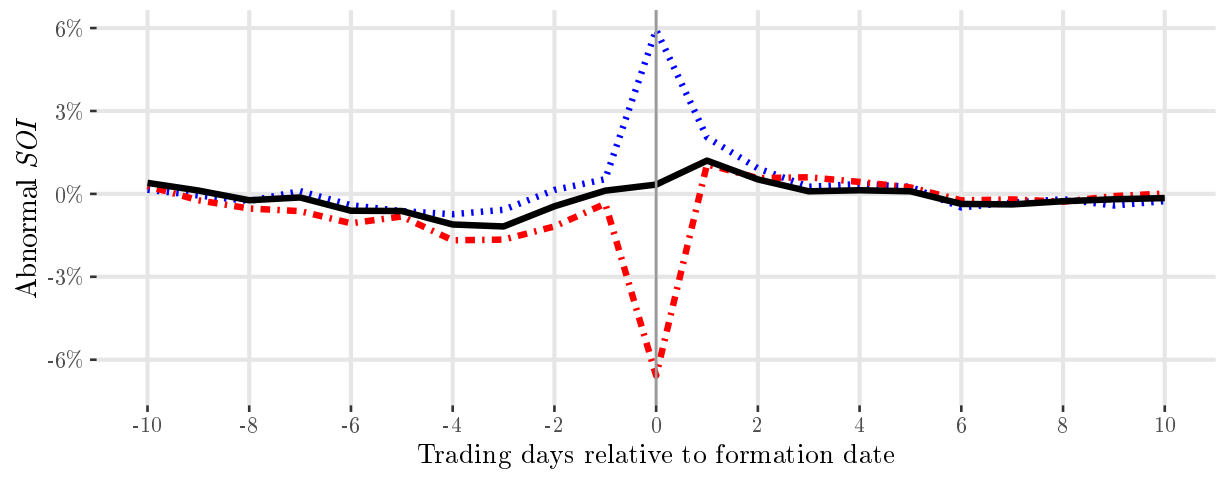

(a) Abnormal stock order imbalance (SOI)

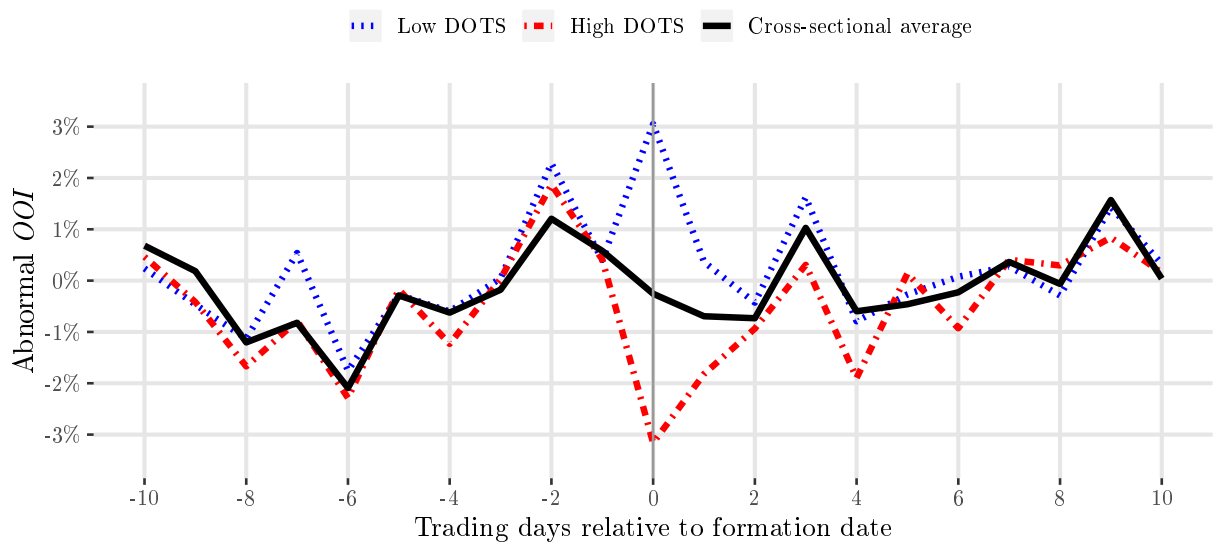

(b) Abnormal option order imbalance (OOI)

\section{Figure 4: Abnormal order imbalances around the DOTS portfolio formation date}

This figure plots the equal-weighted average abnormal stock and option order imbalance (Abnormal SOI and Abnormal OOI, respectively) from ten trading days prior to the sorting date until ten trading days after the sorting date. Stocks are sorted into deciles by DOTS on the last trading day of the month (day zero in the figure). The dash-dotted line corresponds to the portfolio of stocks in the highest DOTS decile, and the dotted line corresponds to the stocks in the lowest DOTS decile. The cross-sectional average (solid line) is added to each plot for reference. The average is computed in the cross-section first, and then averaged across time. For a given stock-date, the Abnormal SOI is computed as the ratio of the dollar values of buyerinitiated minus the seller-initiated trades over the sum of the buyer-initiated and seller-initiated trades in excess of its average during the 30 trading days ending on the 11th trading day (i.e., in the window $[-41,-11]$ ) before the sorting date. The sample covers the period between January 1996 and December 2013, for NYSElisted stocks. The Abnormal $O O I$ is defined for each stock-date as the ratio of the signed share-equivalent volume of trades in options (i.e., the product of the option delta, the number of option contracts, and a dummy for whether the trade is buyer-initiated or seller initiated) for all strikes and maturities over the total share-equivalent volume of option trades (i.e., the product of the absolute delta of the options and the number of contracts) in excess of its average during the 30 trading days ending on the 11th trading day (i.e., in the window $[-41,-11]$ ) before the sorting date. This sample covers the period between April 2008 and December 2013. 


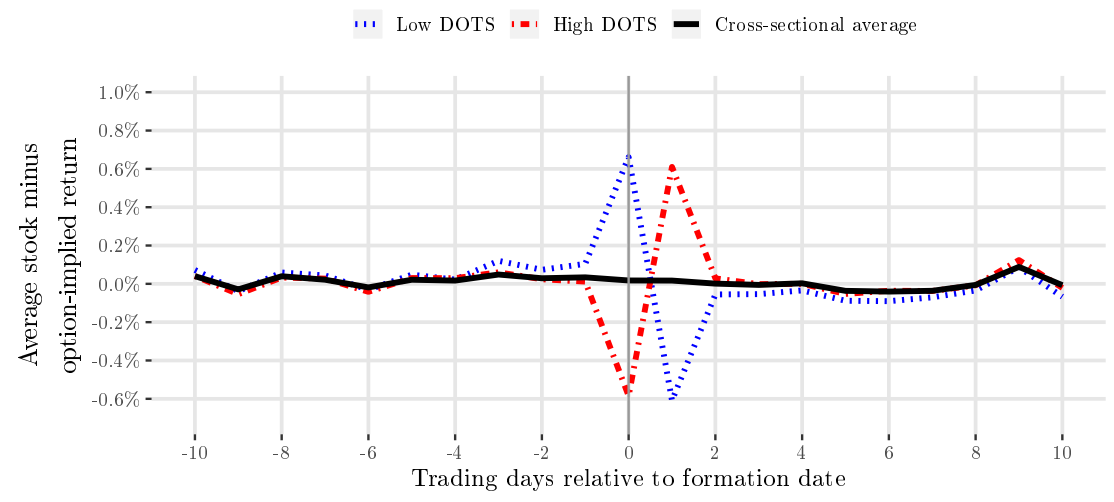

(a) CRSP stock return minus option-implied stock return

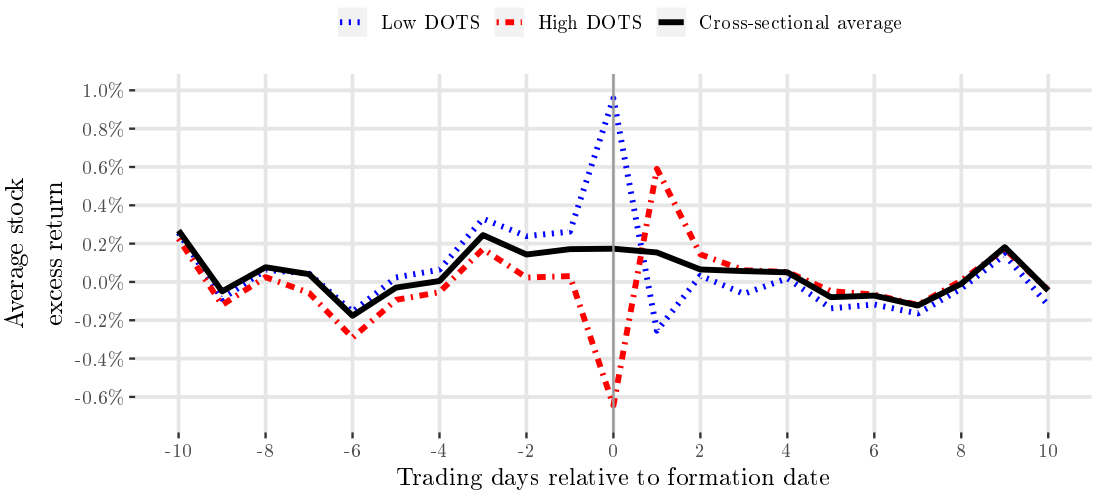

(b) CRSP stock excess return

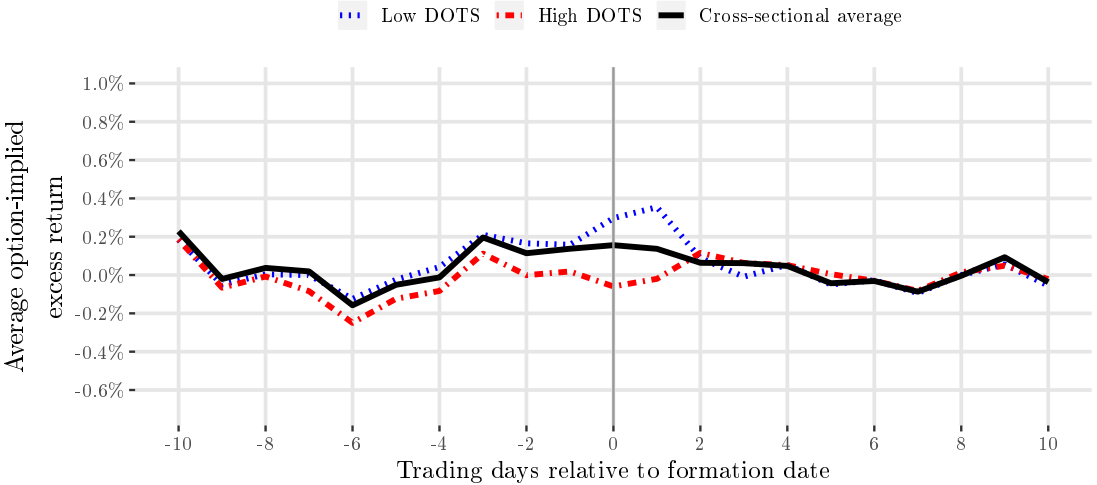

(c) Option-implied stock excess return

\section{Figure 5: Reversals in option-implied stock values and in traded stock prices}

The top panel plots the difference between the average observed stock return and the average option-implied stock return (the changes in the midpoints of the lower and upper bounds given by equations (1) and (2) in the text) from ten trading days prior to the sorting date until ten trading days after the sorting date. The middle and bottom panels split this return difference into the average observed stock return in excess of the risk-free rate (middle panel) and the average option-implied stock return in excess of the risk-free rate (bottom panel). In each graph, the dotted line corresponds to the stocks in the lowest DOTS decile and the dash-dotted line corresponds to the portfolio of stocks in the highest DOTS decile. The average (solid line) of the low and high decile results is added to each plot for reference. The average is computed in the cross-section first, and then averaged across time. Stocks are sorted into deciles by DOTS on the last trading day of the month. The sample covers the period between January 1996 and December 2013. 


\section{Table 1: Characteristics of decile portfolios of stocks sorted by DOTS}

Characteristics of decile portfolios formed by sorting on DOTS at month-end for the period between January 1996 and December 2013 for stocks traded on the NYSE, NASDAQ and AMEX $(\mathrm{N}=297,276)$. The abnormal stock order imbalance (Abnormal SOI), covers NYSE-listed stocks only $(\mathrm{N}=161,100)$. The abnormal option order imbalance (Abnormal OOI) covers the period from April 2008 to December 2013 (N = 91,346). The equal-weighted averages are computed as a time-series average of cross-sectional means. For variables based on option pairs, an equal-weighted average across the pairs is computed, with the exception of $\frac{S^{U}-S^{L}}{\left(S^{U}+S^{L}\right) / 2}$ whose calculation involves weighting by the inverse of the option pair's bid-ask spread. Panel A presents the average DOTS measure. Panel B contains average stock characteristics. Panel C reports average option characteristics. Panel D reports time-series averages of cross-sectional correlations of DOTS with the Cremers and Weinbaum (2010) Call - Put IV spread ("IVS"), the An et al. (2014) monthly change in the Call - Put IV spread (" $\triangle I V S$ "), and the abnormal stock and option order imbalance measures. The italicized variables presented in this table are described in more detail in Appendix A.

Panel A: Difference between Option-Implied and Traded Stock Prices

\begin{tabular}{|c|c|c|c|c|c|c|c|c|c|c|}
\hline & Low DOTS & 2 & 3 & 4 & 5 & 6 & 7 & 8 & 9 & High DOTS \\
\hline $\operatorname{DOTS}(\%)$ & -0.92 & -0.34 & -0.18 & -0.09 & -0.03 & 0.04 & 0.10 & 0.18 & 0.31 & 0.79 \\
\hline \multicolumn{11}{|c|}{ Panel B: Stock-Based Variables } \\
\hline & Low DOTS & 2 & 3 & 4 & 5 & 6 & 7 & 8 & 9 & High DOTS \\
\hline Median market cap (\$B) & 0.77 & 1.61 & 2.52 & 3.03 & 3.64 & 3.74 & 3.46 & 2.59 & 1.71 & 0.81 \\
\hline Stock bid-ask spread (\% of midprice) & 0.82 & 0.60 & 0.54 & 0.51 & 0.47 & 0.45 & 0.47 & 0.50 & 0.57 & 0.77 \\
\hline Idiosyncratic volatility (annualised \%) & 46.73 & 39.06 & 35.72 & 34.27 & 33.00 & 32.28 & 32.96 & 34.76 & 37.71 & 44.64 \\
\hline Abnormal SOI & 0.06 & 0.05 & 0.04 & 0.03 & 0.02 & 0.00 & -0.02 & -0.04 & -0.05 & -0.07 \\
\hline Truncated Abnormal TURN & 0.33 & 0.20 & 0.18 & 0.15 & 0.13 & 0.13 & 0.15 & 0.16 & 0.20 & 0.29 \\
\hline Amihud Illiquidity $(\times 10,000)$ & 1.48 & 0.64 & 0.46 & 0.46 & 0.31 & 0.27 & 0.32 & 0.43 & 0.64 & 1.39 \\
\hline \multicolumn{11}{|c|}{ Panel C: Option-Based Variables } \\
\hline & Low DOTS & 2 & 3 & 4 & 5 & 6 & 7 & 8 & 9 & High DOTS \\
\hline $\operatorname{IVS}(\%)$ & -12.19 & -5.43 & -3.45 & -2.26 & -1.26 & -0.33 & 0.67 & 1.86 & 3.69 & 9.54 \\
\hline$\Delta I V S$ (\% points) & -5.57 & -2.05 & -1.07 & -0.60 & -0.14 & 0.14 & 0.60 & 1.18 & 2.11 & 5.56 \\
\hline$\frac{S^{U}-S^{L}}{\left(S^{U}+S^{L}\right) / 2}(\%)$ & 3.36 & 2.23 & 1.85 & 1.72 & 1.56 & 1.51 & 1.58 & 1.78 & 2.16 & 3.33 \\
\hline Call bid-ask spread ( $\%$ of midprice) & 41.79 & 33.26 & 30.09 & 28.14 & 26.42 & 25.56 & 25.83 & 27.31 & 30.20 & 37.43 \\
\hline Put bid-ask spread (\% of midprice) & 36.03 & 32.56 & 30.80 & 31.23 & 30.90 & 31.53 & 32.13 & 34.17 & 37.22 & 45.31 \\
\hline Calls: \# days since last trade & 4.07 & 3.89 & 3.59 & 3.68 & 3.39 & 3.57 & 3.66 & 3.97 & 4.54 & 5.30 \\
\hline Puts: \# days since last trade & 8.77 & 7.48 & 6.41 & 6.49 & 5.68 & 5.63 & 5.82 & 6.46 & 7.35 & 8.99 \\
\hline Abnormal OOI & 0.03 & 0.02 & 0.01 & 0.00 & -0.00 & -0.01 & -0.01 & -0.00 & -0.02 & -0.03 \\
\hline
\end{tabular}

Panel D: Correlation between DOTS and Option and Stock Market Variables

\begin{tabular}{lcccc}
\hline & $I V S$ & $\Delta I V S$ & $S O I$ & OOI \\
\hline DOTS & 0.953 & 0.442 & -0.166 & -0.027 \\
\hline
\end{tabular}




\section{Table 2: Daily returns of portfolios based on $\boldsymbol{D O T S}, \boldsymbol{I V S}$ and $\Delta \boldsymbol{I V S}$}

This table reports daily average value-weighted returns in excess of the risk-free rate. Returns are calculated from daily closing stock prices ("Traded"), the average of daily closing bid and ask prices ("Midquote"), option-implied stock prices ("Option-implied") and close to open returns ("Overnight") of portfolios of stocks in each decile. On the last trading day of each month, stocks are assigned into deciles by different options market variables. Panel A uses the DOTS on the formation day as a sorting variable. Panel B (IVS) uses the Cremers and Weinbaum (2010) spread between call and put implied volatilities on the formation day with each option pairweighted by the total open interest in the pair. Panel $\mathrm{C}(\Delta I V S)$ uses the An et al. (2014) change over the current month in the difference between the implied volatility of a 30-day maturity call and that of a 30-day maturity put option, both with $|\Delta|$ equal to 0.5 in the OptionMetrics Volatility Surface data set. In each panel, Columns (1)-(3) present results for the full sample, while in Columns (4)-(6) we restrict the sample to contain only stocks with zero volume in all options on the formation day. Portfolio "Low" ("High") contains the $10 \%$ of stocks with the lowest (highest) value of the sorting variable on the last trading day of the month. Day $t-1$ is the formation day. Day $t$ is the day after portfolio formation. Overnight returns are measured from the close on day $t-1$ to the open on day $t$. All returns are computed as value-weighted averages, using the stocks' formation day valuations as weights. Column "High-Low" represents the results from buying the "High" portfolio and shorting the "Low" portfolio. ***, **, and $*$ represent significance at the 1\%,5\%, and $10 \%$ levels, respectively. Newey and West (1987) standard errors are reported in parenthesis.

Panel A: DOTS

\begin{tabular}{|c|c|c|c|c|c|c|c|}
\hline \multirow{2}{*}{\multicolumn{2}{|c|}{$\begin{array}{l}\text { Holding Return } \\
\text { Period }\end{array}$}} & \multicolumn{3}{|c|}{ Full Sample } & \multicolumn{3}{|c|}{ Zero Option Volume } \\
\hline & & $\begin{array}{l}\text { Low } \\
(1)\end{array}$ & $\begin{array}{c}\text { High } \\
(2)\end{array}$ & $\begin{array}{c}\text { High-Low } \\
\text { (3) }\end{array}$ & $\begin{array}{l}\text { Low } \\
(4)\end{array}$ & $\begin{array}{c}\text { High } \\
(5)\end{array}$ & $\begin{array}{l}\text { High-Low } \\
(6)\end{array}$ \\
\hline \multirow{3}{*}{$t-1$} & Traded (a) & $\begin{array}{l}0.740^{* * *} \\
(0.138)\end{array}$ & $\begin{array}{c}-0.697^{* * *} \\
(0.119)\end{array}$ & $\begin{array}{c}-1.438^{* * *} \\
(0.134)\end{array}$ & $\begin{array}{l}0.672^{* * *} \\
(0.094)\end{array}$ & $\begin{array}{c}-0.715^{* * *} \\
(0.081)\end{array}$ & $\begin{array}{c}-1.387^{* * *} \\
(0.083)\end{array}$ \\
\hline & Midquote (b) & $\begin{array}{l}0.450^{* * *} \\
(0.116)\end{array}$ & $\begin{array}{c}-0.424^{* * *} \\
(0.101)\end{array}$ & $\begin{array}{c}-0.874^{* * *} \\
(0.091)\end{array}$ & $\begin{array}{l}0.403^{* * *} \\
(0.096)\end{array}$ & $\begin{array}{c}-0.467^{* * *} \\
(0.095)\end{array}$ & $\begin{array}{c}-0.870^{* * *} \\
(0.109)\end{array}$ \\
\hline & $\begin{array}{ll}\text { Option- } & \text { (c) } \\
\text { Implied }\end{array}$ & $\begin{array}{r}0.203^{*} \\
(0.105) \\
\end{array}$ & $\begin{array}{c}-0.168 \\
(0.106) \\
\end{array}$ & $\begin{array}{c}-0.371^{* * *} \\
(0.099) \\
\end{array}$ & $\begin{array}{c}0.060 \\
(0.072) \\
\end{array}$ & $\begin{array}{c}-0.049 \\
(0.061) \\
\end{array}$ & $\begin{array}{r}-0.109^{*} \\
(0.058) \\
\end{array}$ \\
\hline \multirow{4}{*}{$t$} & Traded (d) & $\begin{array}{c}-0.183 \\
(0.131)\end{array}$ & $\begin{array}{l}0.640^{* * *} \\
(0.121)\end{array}$ & $\begin{array}{l}0.824^{* * *} \\
(0.119)\end{array}$ & $\begin{array}{c}-0.177 \\
(0.131)\end{array}$ & $\begin{array}{l}0.627^{* * *} \\
(0.124)\end{array}$ & $\begin{array}{l}0.804^{* * *} \\
(0.122)\end{array}$ \\
\hline & Midquote (e) & $\begin{array}{c}0.072 \\
(0.114)\end{array}$ & $\begin{array}{c}0.291^{* *} \\
(0.117)\end{array}$ & $\begin{array}{l}0.218^{* * *} \\
(0.072)\end{array}$ & $\begin{array}{c}0.074 \\
(0.120)\end{array}$ & $\begin{array}{l}0.325^{* * *} \\
(0.110)\end{array}$ & $\begin{array}{l}0.251^{* * *} \\
(0.077)\end{array}$ \\
\hline & $\begin{array}{l}\text { Option- (f) } \\
\text { Implied }\end{array}$ & $\begin{array}{l}0.270^{* * *} \\
(0.094)\end{array}$ & $\begin{array}{c}0.031 \\
(0.106) \\
\end{array}$ & $\begin{array}{c}-0.239^{* * *} \\
(0.080)\end{array}$ & $\begin{array}{l}0.371^{* * *} \\
(0.081)\end{array}$ & $\begin{array}{c}-0.094 \\
(0.103)\end{array}$ & $\begin{array}{c}-0.465^{* * *} \\
(0.099)\end{array}$ \\
\hline & Overnight (g) & $\begin{array}{r}-0.145^{*} \\
(0.086)\end{array}$ & $\begin{array}{l}0.376^{* * *} \\
(0.069)\end{array}$ & $\begin{array}{l}0.521^{* * *} \\
(0.103)\end{array}$ & $\begin{array}{r}-0.124^{*} \\
(0.067)\end{array}$ & $\begin{array}{l}0.256^{* * *} \\
(0.056)\end{array}$ & $\begin{array}{l}0.381^{* * *} \\
(0.071)\end{array}$ \\
\hline
\end{tabular}


Table 2: Continued

Panel B: IVS

\begin{tabular}{|c|c|c|c|c|c|c|c|}
\hline \multirow{2}{*}{\multicolumn{2}{|c|}{$\begin{array}{l}\text { Holding Return } \\
\text { Period }\end{array}$}} & \multicolumn{3}{|c|}{ Full Sample } & \multicolumn{3}{|c|}{ Zero Option Volume } \\
\hline & & $\begin{array}{l}\text { Low } \\
(1)\end{array}$ & $\begin{array}{c}\text { High } \\
(2)\end{array}$ & $\begin{array}{l}\text { High-Low } \\
\text { (3) }\end{array}$ & $\begin{array}{l}\text { Low } \\
(4)\end{array}$ & $\begin{array}{c}\text { High } \\
(5)\end{array}$ & $\begin{array}{l}\text { High-Low } \\
\text { (6) }\end{array}$ \\
\hline \multirow{3}{*}{$t-1$} & Traded (a) & $\begin{array}{l}0.849^{* * *} \\
(0.139)\end{array}$ & $\begin{array}{c}-0.592^{* * *} \\
(0.121)\end{array}$ & $\begin{array}{c}-1.440^{* * *} \\
(0.130)\end{array}$ & $\begin{array}{l}0.681^{* * *} \\
(0.099)\end{array}$ & $\begin{array}{c}-0.690^{* * *} \\
(0.079)\end{array}$ & $\begin{array}{l}-1.371^{* * *} \\
(0.082)\end{array}$ \\
\hline & Midquote (b) & $\begin{array}{l}0.548^{* * *} \\
(0.119)\end{array}$ & $\begin{array}{l}-0.363^{* * *} \\
(0.105)\end{array}$ & $\begin{array}{l}-0.911^{* * *} \\
(0.096)\end{array}$ & $\begin{array}{l}0.428^{* * *} \\
(0.100)\end{array}$ & $\begin{array}{l}-0.457^{* * *} \\
(0.090)\end{array}$ & $\begin{array}{l}-0.884^{* * *} \\
(0.106)\end{array}$ \\
\hline & $\begin{array}{l}\text { Option- } \\
\text { Implied }\end{array}$ & $\begin{array}{l}0.334^{* * *} \\
(0.112)\end{array}$ & $\begin{array}{c}-0.157 \\
(0.110)\end{array}$ & $\begin{array}{l}-0.491^{* * *} \\
(0.112)\end{array}$ & $\begin{array}{c}0.135^{*} \\
(0.073)\end{array}$ & $\begin{array}{c}-0.060 \\
(0.060)\end{array}$ & $\begin{array}{l}-0.194^{* * *} \\
(0.059)\end{array}$ \\
\hline \multirow{4}{*}{$t$} & Traded (d) & $\begin{array}{c}-0.220 \\
(0.140)\end{array}$ & $\begin{array}{l}0.640^{* * *} \\
(0.118)\end{array}$ & $\begin{array}{l}0.860^{* * *} \\
(0.125)\end{array}$ & $\begin{array}{c}-0.153 \\
(0.131)\end{array}$ & $\begin{array}{l}0.602^{* * *} \\
(0.132)\end{array}$ & $\begin{array}{l}0.755^{* * *} \\
(0.126)\end{array}$ \\
\hline & Midquote (e) & $\begin{array}{c}0.033 \\
(0.126)\end{array}$ & $\begin{array}{l}0.356^{* * *} \\
(0.101)\end{array}$ & $\begin{array}{l}0.322^{* * *} \\
(0.084)\end{array}$ & $\begin{array}{c}0.088 \\
(0.123)\end{array}$ & $\begin{array}{l}0.331^{* * *} \\
(0.117)\end{array}$ & $\begin{array}{l}0.243^{* * *} \\
(0.082)\end{array}$ \\
\hline & $\begin{array}{l}\text { Option- (f) } \\
\text { Implied }\end{array}$ & $\begin{array}{l}0.225^{* *} \\
(0.106)\end{array}$ & $\begin{array}{c}0.128 \\
(0.103) \\
\end{array}$ & $\begin{array}{c}-0.097 \\
(0.091)\end{array}$ & $\begin{array}{l}0.323^{* * *} \\
(0.084)\end{array}$ & $\begin{array}{c}-0.069 \\
(0.106)\end{array}$ & $\begin{array}{c}-0.392^{* * *} \\
(0.105)\end{array}$ \\
\hline & Overnight (g) & $\begin{array}{c}-0.052 \\
(0.077)\end{array}$ & $\begin{array}{l}0.366^{* * *} \\
(0.072)\end{array}$ & $\begin{array}{l}0.417^{* * *} \\
(0.086)\end{array}$ & $\begin{array}{r}-0.112^{*} \\
(0.066)\end{array}$ & $\begin{array}{l}0.260^{* * *} \\
(0.058)\end{array}$ & $\begin{array}{l}0.372^{* * *} \\
(0.073)\end{array}$ \\
\hline
\end{tabular}

Panel C: $\Delta I V S$

\begin{tabular}{|c|c|c|c|c|c|c|c|}
\hline \multirow{2}{*}{\multicolumn{2}{|c|}{$\begin{array}{l}\text { Holding Return } \\
\text { Period }\end{array}$}} & \multicolumn{3}{|c|}{ Full Sample } & \multicolumn{3}{|c|}{ Zero Option Volume } \\
\hline & & $\begin{array}{l}\text { Low } \\
(1)\end{array}$ & $\begin{array}{l}\text { High } \\
(2)\end{array}$ & $\begin{array}{l}\text { High-Low } \\
\quad(3)\end{array}$ & $\begin{array}{l}\text { Low } \\
(4)\end{array}$ & $\begin{array}{c}\text { High } \\
(5)\end{array}$ & $\begin{array}{l}\text { High-Low } \\
\quad(6)\end{array}$ \\
\hline \multirow{3}{*}{$t-1$} & Traded & $\begin{array}{l}0.637^{* * *} \\
(0.136)\end{array}$ & $\begin{array}{c}-0.272^{\text {*** }} \\
(0.097)\end{array}$ & $\begin{array}{c}-0.909^{* * *} \\
(0.096)\end{array}$ & $\begin{array}{l}0.514^{* * *} \\
(0.105)\end{array}$ & $\begin{array}{c}-0.398^{* * *} \\
(0.082)\end{array}$ & $\begin{array}{c}-0.912^{\text {*** }} \\
(0.072)\end{array}$ \\
\hline & Midquote (b) & $\begin{array}{l}0.448^{* * *} \\
(0.121)\end{array}$ & $\begin{array}{r}-0.155^{*} \\
(0.094)\end{array}$ & $\begin{array}{c}-0.604^{* * *} \\
(0.085)\end{array}$ & $\begin{array}{l}0.347^{* * *} \\
(0.103)\end{array}$ & $\begin{array}{c}-0.260^{* * *} \\
(0.086)\end{array}$ & $\begin{array}{c}-0.607^{* * *} \\
(0.083)\end{array}$ \\
\hline & $\begin{array}{l}\text { Option- } \\
\text { Implied }\end{array}$ & $\begin{array}{l}0.303^{* * *} \\
(0.114) \\
\end{array}$ & $\begin{array}{c}0.013 \\
(0.089) \\
\end{array}$ & $\begin{array}{c}-0.290^{* * *} \\
(0.079)\end{array}$ & $\begin{array}{c}0.120 \\
(0.084) \\
\end{array}$ & $\begin{array}{c}-0.011 \\
(0.070) \\
\end{array}$ & $\begin{array}{c}-0.131^{* *} \\
(0.052) \\
\end{array}$ \\
\hline \multirow{4}{*}{$t$} & Traded $\quad(d)$ & $\begin{array}{c}-0.055 \\
(0.126)\end{array}$ & $\begin{array}{l}0.470^{* * *} \\
(0.128)\end{array}$ & $\begin{array}{l}0.525^{* * *} \\
(0.075)\end{array}$ & $\begin{array}{c}-0.045 \\
(0.117)\end{array}$ & $\begin{array}{l}0.442^{* * *} \\
(0.121)\end{array}$ & $\begin{array}{l}0.487^{* * *} \\
(0.100)\end{array}$ \\
\hline & Midquote (e) & $\begin{array}{c}0.102 \\
(0.117) \\
\end{array}$ & $\begin{array}{c}0.286^{* *} \\
(0.116) \\
\end{array}$ & $\begin{array}{l}0.184^{* * *} \\
(0.060)\end{array}$ & $\begin{array}{c}0.091 \\
(0.109) \\
\end{array}$ & $\begin{array}{l}0.241^{* *} \\
(0.114)\end{array}$ & $\begin{array}{l}0.150^{* *} \\
(0.075)\end{array}$ \\
\hline & $\begin{array}{ll}\text { Option- } & (\mathrm{f}) \\
\text { Implied }\end{array}$ & $\begin{array}{c}0.224^{* *} \\
(0.111)\end{array}$ & $\begin{array}{c}0.122 \\
(0.114) \\
\end{array}$ & $\begin{array}{r}-0.101^{*} \\
(0.061) \\
\end{array}$ & $\begin{array}{l}0.236^{* * *} \\
(0.081)\end{array}$ & $\begin{array}{c}0.014 \\
(0.096) \\
\end{array}$ & $\begin{array}{c}-0.222^{* * *} \\
(0.084)\end{array}$ \\
\hline & Overnight (g) & $\begin{array}{c}-0.074 \\
(0.090)\end{array}$ & $\begin{array}{c}0.198^{* *} \\
(0.083)\end{array}$ & $\begin{array}{l}0.272^{* * *} \\
(0.075)\end{array}$ & $\begin{array}{c}-0.081 \\
(0.063)\end{array}$ & $\begin{array}{l}0.203^{* * *} \\
(0.053)\end{array}$ & $\begin{array}{l}0.285^{* * *} \\
(0.058)\end{array}$ \\
\hline
\end{tabular}




\section{Table 3: Double sort by $\boldsymbol{C P P}$ and DOTS}

This table reports daily average value-weighted returns in excess of the market return on the first trading day following portfolio formation. Returns are calculated from daily closing stock prices. Panel A reports returns on a single sort by DOTS for the sample for which both Composite Proxy for Price Pressure $(C P P)$ and $D O T S$ are available. Panel B uses a sequential sort by $C P P$ and DOTS. On the last trading day of each month, stocks are assigned into quintiles by their CPP level, which combines a stock's (i) abnormal stock order imbalance on the formation day (Abnormal $S O I$ ), (ii) stock return on the formation day in excess of the market, and (iii) abnormal stock turnover (TURN) on the formation day signed by the stock return. Stocks in the lowest $C P P$ quintile are most likely to experience selling pressure, and stocks in the highest $C P P$ quintile are most likely to experience buying pressure. Within each CPP quintile, stocks are then sorted into quintiles by their DOTS value on the formation day. Row "High DOTS - Low DOTS" represents the results from buying the stocks in the highest DOTS quintile and selling the stocks in the lowest DOTS quintile for a given CPP quintile. ***, **, and * represent significance at the $1 \%, 5 \%$, and $10 \%$ levels, respectively. Newey and West (1987) standard errors are reported in parenthesis.

Panel A: Univariate sort by DOTS

\begin{tabular}{cccccc}
\hline Low DOTS & 2 & 3 & 4 & High DOTS & High DOTS - Low DOTS \\
\hline$-0.142^{* * *}$ & $-0.070^{* * *}$ & -0.012 & $0.090^{* *}$ & $0.236^{* * *}$ & $0.379^{* * *}$ \\
$(0.036)$ & $(0.023)$ & $(0.028)$ & $(0.036)$ & $(0.041)$ & $(0.057)$ \\
\hline
\end{tabular}

Panel B: Sequential sort on Price Pressure and DOTS

\begin{tabular}{cccccc}
\hline & Selling Pressure & 2 & 3 & 4 & Buying Pressure \\
\hline Low DOTS & 0.041 & -0.03 & -0.12 & -0.098 & $-0.384^{* * *}$ \\
2 & $(0.064)$ & $(0.059)$ & $(0.082)$ & $(0.063)$ & $(0.078)$ \\
& $0.160^{* * *}$ & 0.018 & -0.037 & $-0.106^{* * *}$ & $-0.317^{* * *}$ \\
3 & $(0.057)$ & $(0.052)$ & $(0.033)$ & $(0.040)$ & $(0.058)$ \\
& $0.124^{* *}$ & 0.097 & -0.065 & -0.053 & $-0.228^{* * *}$ \\
& $(0.054)$ & $(0.061)$ & $(0.047)$ & $(0.052)$ & $(0.057)$ \\
High DOTS & $0.244^{* * *}$ & $0.112^{* *}$ & $0.083^{*}$ & -0.018 & $-0.149^{* * *}$ \\
& $(0.073)$ & $(0.049)$ & $(0.046)$ & $(0.049)$ & $(0.047)$ \\
High DOTS - Low DOTS & $0.438^{* * *}$ & $0.305^{* * *}$ & 0.054 & 0.075 & 0.022 \\
& $(0.089)$ & $(0.064)$ & $(0.052)$ & $(0.047)$ & $(0.052)$ \\
\hline
\end{tabular}




\section{Table 4: Univariate stock portfolios based on $\boldsymbol{D O T S}, \boldsymbol{I V S}$ and $\Delta \boldsymbol{I V S}$ - weekly and monthly holding periods}

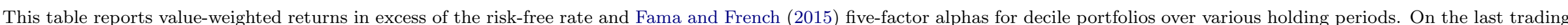

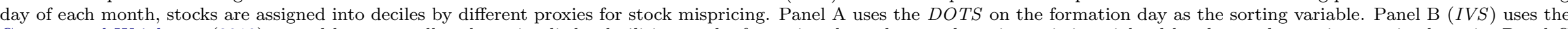

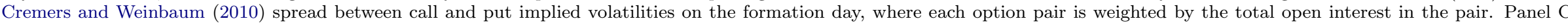

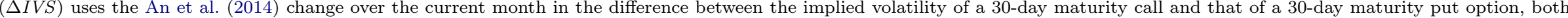

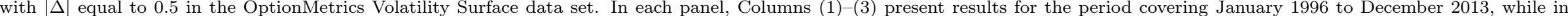

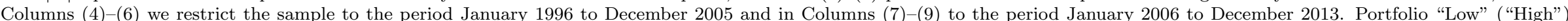

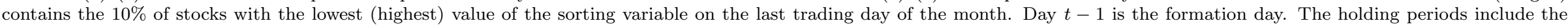

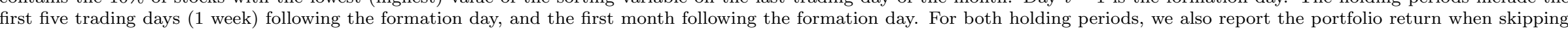

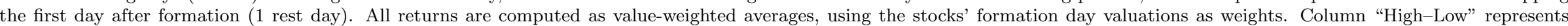

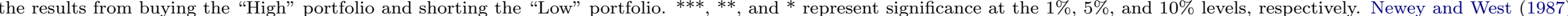
standard errors are reported in parenthesis.

Panel A: DOTS

\begin{tabular}{|c|c|c|c|c|c|c|c|c|c|c|}
\hline \multirow[b]{2}{*}{ g } & & \multicolumn{3}{|c|}{ Full Sample } & \multicolumn{3}{|c|}{ 1996-2005 } & \multicolumn{3}{|c|}{ 2006-2013 } \\
\hline & & $\begin{array}{l}\text { Low } \\
(1)\end{array}$ & $\begin{array}{l}\text { High } \\
(2)\end{array}$ & $\begin{array}{l}\text { High-Low } \\
\text { (3) }\end{array}$ & $\begin{array}{l}\text { Low } \\
(4)\end{array}$ & $\begin{array}{c}\text { High } \\
(5)\end{array}$ & $\begin{array}{l}\text { High-Low } \\
\text { (6) }\end{array}$ & $\begin{array}{l}\text { Low } \\
(7)\end{array}$ & $\begin{array}{c}\text { High } \\
(8)\end{array}$ & $\begin{array}{c}\text { High-Low } \\
(9)\end{array}$ \\
\hline$t-1$ & Return & $\begin{array}{l}0.740^{* * *} \\
(0.138)\end{array}$ & $\begin{array}{c}-0.697^{* * *} \\
(0.119)\end{array}$ & $\begin{array}{c}-1.438^{* * *} \\
(0.134)\end{array}$ & $\begin{array}{l}1.002^{* * *} \\
(0.171)\end{array}$ & $\begin{array}{c}-0.753^{* * *} \\
(0.191)\end{array}$ & $\begin{array}{c}-1.755^{* * *} \\
(0.190)\end{array}$ & $\begin{array}{c}0.414^{* *} \\
(0.189)\end{array}$ & $\begin{array}{c}-0.628^{* * *} \\
(0.119)\end{array}$ & $\begin{array}{c}-1.041^{* * *} \\
(0.115)\end{array}$ \\
\hline$t$ & Return & $\begin{array}{c}-0.183 \\
(0.131)\end{array}$ & $\begin{array}{l}0.640^{* * *} \\
(0.121)\end{array}$ & $\begin{array}{l}0.824^{* * *} \\
(0.119)\end{array}$ & $\begin{array}{c}-0.263 \\
(0.170)\end{array}$ & $\begin{array}{l}0.941^{* * *} \\
(0.121)\end{array}$ & $\begin{array}{l}1.204^{* * *} \\
(0.147)\end{array}$ & $\begin{array}{c}-0.083 \\
(0.201)\end{array}$ & $\begin{array}{c}0.265 \\
(0.186)\end{array}$ & $\begin{array}{l}0.349^{* * *} \\
(0.093)\end{array}$ \\
\hline $\begin{array}{l}1 \text { Week } \\
\text { (no rest) }\end{array}$ & FF5 alpha (c) & $\begin{array}{c}-0.445^{* * *} \\
(0.127)\end{array}$ & $\begin{array}{l}0.365^{* * *} \\
(0.141)\end{array}$ & $\begin{array}{l}0.809^{* * *} \\
(0.178)\end{array}$ & $\begin{array}{c}-0.751^{* * *} \\
(0.191)\end{array}$ & $\begin{array}{l}0.584^{* * *} \\
(0.198)\end{array}$ & $\begin{array}{l}1.335^{* * *} \\
(0.224)\end{array}$ & $\begin{array}{c}-0.159 \\
(0.147)\end{array}$ & $\begin{array}{c}0.050 \\
(0.089)\end{array}$ & $\begin{array}{c}0.210 \\
(0.200)\end{array}$ \\
\hline $\begin{array}{l}1 \text { Week } \\
(1 \text { rest day })\end{array}$ & FF5 alpha (d) & $\begin{array}{c}-0.028 \\
(0.080) \\
\end{array}$ & $\begin{array}{c}-0.009 \\
(0.109) \\
\end{array}$ & $\begin{array}{c}0.018 \\
(0.130) \\
\end{array}$ & $\begin{array}{c}-0.113 \\
(0.111)\end{array}$ & $\begin{array}{c}0.069 \\
(0.163) \\
\end{array}$ & $\begin{array}{c}0.182 \\
(0.178) \\
\end{array}$ & $\begin{array}{c}0.026 \\
(0.108)\end{array}$ & $\begin{array}{c}-0.066 \\
(0.084)\end{array}$ & $\begin{array}{c}-0.092 \\
(0.158)\end{array}$ \\
\hline $\begin{array}{l}1 \text { Month } \\
\text { (no rest) }\end{array}$ & FF5 alpha (e) & $\begin{array}{l}-0.615^{* * *} \\
(0.197)\end{array}$ & $\begin{array}{c}0.342 \\
(0.217)\end{array}$ & $\begin{array}{l}0.957^{* * *} \\
(0.293)\end{array}$ & $\begin{array}{l}-0.980^{* * *} \\
(0.288)\end{array}$ & $\begin{array}{c}0.462 \\
(0.364)\end{array}$ & $\begin{array}{l}1.442^{* * *} \\
(0.426)\end{array}$ & $\begin{array}{c}-0.227 \\
(0.193)\end{array}$ & $\begin{array}{c}0.060 \\
(0.191)\end{array}$ & $\begin{array}{c}0.287 \\
(0.308)\end{array}$ \\
\hline $\begin{array}{l}1 \text { Month } \\
\text { (1 rest day) }\end{array}$ & FF5 alpha (f) & $\begin{array}{c}-0.184 \\
(0.179) \\
\end{array}$ & $\begin{array}{c}0.033 \\
(0.188) \\
\end{array}$ & $\begin{array}{c}0.217 \\
(0.246) \\
\end{array}$ & $\begin{array}{c}-0.319 \\
(0.276) \\
\end{array}$ & $\begin{array}{c}0.005 \\
(0.314) \\
\end{array}$ & $\begin{array}{c}0.324 \\
(0.367) \\
\end{array}$ & $\begin{array}{c}-0.029 \\
(0.181) \\
\end{array}$ & $\begin{array}{c}-0.113 \\
(0.198) \\
\end{array}$ & $\begin{array}{c}-0.084 \\
(0.300) \\
\end{array}$ \\
\hline
\end{tabular}




\section{Table 4: Continued}

Panel B: $I V S$

\begin{tabular}{|c|c|c|c|c|c|c|c|c|c|c|}
\hline \multirow[b]{2}{*}{$\begin{array}{l}\text { Holding } \\
\text { Period }\end{array}$} & & \multicolumn{3}{|c|}{ Full Sample } & \multicolumn{3}{|c|}{ 1996-2005 } & \multicolumn{3}{|c|}{ 2006-2013 } \\
\hline & & $\begin{array}{l}\text { Low } \\
(1)\end{array}$ & $\begin{array}{l}\text { High } \\
(2)\end{array}$ & $\begin{array}{c}\text { High-Low } \\
(3)\end{array}$ & $\begin{array}{c}\text { Low } \\
(4)\end{array}$ & $\begin{array}{l}\text { High } \\
(5)\end{array}$ & $\begin{array}{l}\text { High-Low } \\
(6)\end{array}$ & $\begin{array}{c}\text { Low } \\
(7)\end{array}$ & $\begin{array}{c}\text { High } \\
(8)\end{array}$ & $\begin{array}{l}\text { High-Low } \\
(9)\end{array}$ \\
\hline$t-1$ & Return & $\begin{array}{l}0.849^{* * *} \\
(0.139)\end{array}$ & $\begin{array}{c}-0.592^{* * *} \\
(0.121)\end{array}$ & $\begin{array}{c}-1.440^{* * *} \\
(0.130)\end{array}$ & $\begin{array}{l}1.110^{* * *} \\
(0.174)\end{array}$ & $\begin{array}{c}-0.704^{* * *} \\
(0.181)\end{array}$ & $\begin{array}{c}-1.814^{* * *} \\
(0.164)\end{array}$ & $\begin{array}{l}0.522^{* * *} \\
(0.190)\end{array}$ & $\begin{array}{c}-0.451^{* * *} \\
(0.144)\end{array}$ & $\begin{array}{c}-0.973^{* * *} \\
(0.121)\end{array}$ \\
\hline$t$ & Return & $\begin{array}{c}-0.220 \\
(0.140)\end{array}$ & $\begin{array}{l}0.640^{* * *} \\
(0.118)\end{array}$ & $\begin{array}{l}0.860^{* * *} \\
(0.125)\end{array}$ & $\begin{array}{c}-0.242 \\
(0.174)\end{array}$ & $\begin{array}{l}0.953^{* * *} \\
(0.111)\end{array}$ & $\begin{array}{l}1.194^{* * *} \\
(0.171)\end{array}$ & $\begin{array}{c}-0.192 \\
(0.225)\end{array}$ & $\begin{array}{c}0.249 \\
(0.178)\end{array}$ & $\begin{array}{l}0.442^{* * *} \\
(0.098)\end{array}$ \\
\hline $\begin{array}{l}1 \text { Week } \\
\text { (no rest) }\end{array}$ & FF5 alpha (c) & $\begin{array}{c}-0.517^{* * *} \\
(0.152)\end{array}$ & $\begin{array}{l}0.472^{* * *} \\
(0.166)\end{array}$ & $\begin{array}{l}0.989^{* * *} \\
(0.225)\end{array}$ & $\begin{array}{c}-0.822^{* * *} \\
(0.256)\end{array}$ & $\begin{array}{l}0.845^{* * *} \\
(0.254)\end{array}$ & $\begin{array}{l}1.667^{* * *} \\
(0.296)\end{array}$ & $\begin{array}{c}-0.163 \\
(0.122)\end{array}$ & $\begin{array}{c}-0.023 \\
(0.119)\end{array}$ & $\begin{array}{c}0.139 \\
(0.183)\end{array}$ \\
\hline $\begin{array}{l}1 \text { Week } \\
(1 \text { rest day })\end{array}$ & FF5 alpha (d) & $\begin{array}{c}-0.072 \\
(0.117) \\
\end{array}$ & $\begin{array}{c}0.060 \\
(0.097) \\
\end{array}$ & $\begin{array}{c}0.132 \\
(0.150) \\
\end{array}$ & $\begin{array}{c}-0.262 \\
(0.192) \\
\end{array}$ & $\begin{array}{c}0.237^{*} \\
(0.137) \\
\end{array}$ & $\begin{array}{c}0.499^{* *} \\
(0.203) \\
\end{array}$ & $\begin{array}{c}0.120 \\
(0.106) \\
\end{array}$ & $\begin{array}{c}-0.121 \\
(0.089) \\
\end{array}$ & $\begin{array}{c}-0.241 \\
(0.151) \\
\end{array}$ \\
\hline $\begin{array}{l}1 \text { Month } \\
\text { (no rest) }\end{array}$ & FF5 alpha (e) & $\begin{array}{c}-1.005^{* * *} \\
(0.263)\end{array}$ & $\begin{array}{c}0.479^{*} \\
(0.247) \\
\end{array}$ & $\begin{array}{l}1.484^{* * *} \\
(0.352)\end{array}$ & $\begin{array}{c}-1.629^{* * *} \\
(0.376)\end{array}$ & $\begin{array}{c}0.692 \\
(0.424) \\
\end{array}$ & $\begin{array}{l}2.321^{* * *} \\
(0.471)\end{array}$ & $\begin{array}{c}-0.294 \\
(0.258) \\
\end{array}$ & $\begin{array}{c}0.129 \\
(0.230) \\
\end{array}$ & $\begin{array}{c}0.422 \\
(0.413) \\
\end{array}$ \\
\hline $\begin{array}{l}1 \text { Month } \\
\text { (1 rest day) }\end{array}$ & FF5 alpha (f) & $\begin{array}{c}-0.539^{* *} \\
(0.239) \\
\end{array}$ & $\begin{array}{c}0.122 \\
(0.209)\end{array}$ & $\begin{array}{l}0.662^{* *} \\
(0.285)\end{array}$ & $\begin{array}{c}-0.982^{* * *} \\
(0.348)\end{array}$ & $\begin{array}{c}0.148 \\
(0.369)\end{array}$ & $\begin{array}{l}1.130^{* * *} \\
(0.393)\end{array}$ & $\begin{array}{c}0.001 \\
(0.244)\end{array}$ & $\begin{array}{c}-0.018 \\
(0.185)\end{array}$ & $\begin{array}{c}-0.019 \\
(0.368)\end{array}$ \\
\hline
\end{tabular}

Panel C: $\Delta I V S$

\begin{tabular}{|c|c|c|c|c|c|c|c|c|c|c|}
\hline \multirow[b]{2}{*}{$\begin{array}{l}\text { Holding } \\
\text { Period }\end{array}$} & & \multicolumn{3}{|c|}{ Full Sample } & \multicolumn{3}{|c|}{ 1996-2005 } & \multicolumn{3}{|c|}{ 2006-2013 } \\
\hline & & $\begin{array}{l}\text { Low } \\
(1)\end{array}$ & $\begin{array}{l}\text { High } \\
(2)\end{array}$ & $\begin{array}{l}\text { High-Low } \\
\text { (3) }\end{array}$ & $\begin{array}{l}\text { Low } \\
(4)\end{array}$ & $\begin{array}{l}\text { High } \\
(5)\end{array}$ & $\begin{array}{l}\text { High-Low } \\
\quad(6)\end{array}$ & $\begin{array}{l}\text { Low } \\
(7)\end{array}$ & $\begin{array}{l}\text { High } \\
(8)\end{array}$ & $\begin{array}{l}\text { High-Low } \\
\quad(9)\end{array}$ \\
\hline$t-1$ & Return & $\begin{array}{l}0.637^{* * *} \\
(0.136)\end{array}$ & $\begin{array}{c}-0.272^{* * *} \\
(0.097)\end{array}$ & $\begin{array}{c}-0.909^{* * *} \\
(0.096)\end{array}$ & $\begin{array}{l}0.829^{* * *} \\
(0.183)\end{array}$ & $\begin{array}{r}-0.242^{*} \\
(0.135)\end{array}$ & $\begin{array}{c}-1.071^{* * *} \\
(0.142)\end{array}$ & $\begin{array}{c}0.399^{* *} \\
(0.183)\end{array}$ & $\begin{array}{c}-0.309^{* *} \\
(0.140)\end{array}$ & $\begin{array}{c}-0.708^{* * *} \\
(0.098)\end{array}$ \\
\hline$t$ & Return & $\begin{array}{c}-0.055 \\
(0.126)\end{array}$ & $\begin{array}{l}0.470^{* * *} \\
(0.128)\end{array}$ & $\begin{array}{l}0.525^{* * *} \\
(0.075)\end{array}$ & $\begin{array}{c}0.027 \\
(0.154)\end{array}$ & $\begin{array}{l}0.717^{* * *} \\
(0.143)\end{array}$ & $\begin{array}{l}0.690^{* * *} \\
(0.091)\end{array}$ & $\begin{array}{c}-0.157 \\
(0.203)\end{array}$ & $\begin{array}{c}0.164 \\
(0.200)\end{array}$ & $\begin{array}{l}0.321^{* * *} \\
(0.100)\end{array}$ \\
\hline $\begin{array}{l}1 \text { Week } \\
\text { (no rest) }\end{array}$ & FF5 alpha (c) & $\begin{array}{c}-0.319^{* * *} \\
(0.110) \\
\end{array}$ & $\begin{array}{l}0.288^{* *} \\
(0.117)\end{array}$ & $\begin{array}{l}0.608^{* * *} \\
(0.175)\end{array}$ & $\begin{array}{c}-0.527^{* * *} \\
(0.158)\end{array}$ & $\begin{array}{l}0.424^{* *} \\
(0.170)\end{array}$ & $\begin{array}{l}0.950^{* * *} \\
(0.222)\end{array}$ & $\begin{array}{c}-0.095 \\
(0.130)\end{array}$ & $\begin{array}{c}0.046 \\
(0.106)\end{array}$ & $\begin{array}{c}0.141 \\
(0.196)\end{array}$ \\
\hline $\begin{array}{l}1 \text { Week } \\
(1 \text { rest day })\end{array}$ & FF5 alpha (d) & $\begin{array}{c}-0.039 \\
(0.086) \\
\end{array}$ & $\begin{array}{c}0.075 \\
(0.094) \\
\end{array}$ & $\begin{array}{c}0.114 \\
(0.123) \\
\end{array}$ & $\begin{array}{r}-0.222^{*} \\
(0.114) \\
\end{array}$ & $\begin{array}{c}0.088 \\
(0.132) \\
\end{array}$ & $\begin{array}{l}0.310^{* *} \\
(0.151) \\
\end{array}$ & $\begin{array}{c}0.126 \\
(0.097) \\
\end{array}$ & $\begin{array}{c}0.026 \\
(0.107)\end{array}$ & $\begin{array}{c}-0.100 \\
(0.164) \\
\end{array}$ \\
\hline $\begin{array}{l}1 \text { Month } \\
\text { (no rest) }\end{array}$ & FF5 alpha (e) & $\begin{array}{c}-0.471^{* *} \\
(0.235) \\
\end{array}$ & $\begin{array}{c}0.354^{*} \\
(0.196) \\
\end{array}$ & $\begin{array}{l}0.825^{* * *} \\
(0.316)\end{array}$ & $\begin{array}{c}-0.954^{* * *} \\
(0.338) \\
\end{array}$ & $\begin{array}{c}0.436 \\
(0.294) \\
\end{array}$ & $\begin{array}{l}1.390^{* * *} \\
(0.405)\end{array}$ & $\begin{array}{c}0.145 \\
(0.193) \\
\end{array}$ & $\begin{array}{c}0.139 \\
(0.168) \\
\end{array}$ & $\begin{array}{c}-0.007 \\
(0.304) \\
\end{array}$ \\
\hline $\begin{array}{l}1 \text { Month } \\
\text { (1 rest day) }\end{array}$ & FF5 alpha (f) & $\begin{array}{c}-0.149 \\
(0.228)\end{array}$ & $\begin{array}{c}0.097 \\
(0.179)\end{array}$ & $\begin{array}{l}0.246 \\
(0.272)\end{array}$ & $\begin{array}{c}-0.609^{*} \\
(0.335)\end{array}$ & $\begin{array}{c}0.044 \\
(0.267)\end{array}$ & $\begin{array}{c}0.653^{*} \\
(0.361)\end{array}$ & $\begin{array}{l}0.449^{* * *} \\
(0.174)\end{array}$ & $\begin{array}{c}0.060 \\
(0.183)\end{array}$ & $\begin{array}{c}-0.389 \\
(0.280)\end{array}$ \\
\hline
\end{tabular}




\section{Table 5: Daily returns of DOTS portfolios and return-matched portfolios}

This table reports daily average value-weighted returns in excess of the risk-free rate for portfolios of stocks in the extreme DOTS deciles ("DOTS Sample") and portfolios of stocks with matching returns on the formation day ("Matched-Return Sample"). On the last trading day of each month, stocks are assigned into deciles by their DOTS value on that formation day. From the set of stocks that are not in the extreme DOTS deciles and using sampling with replacement, matching stocks are selected as having the smallest absolute difference in return to a stock in the extreme DOTS decile, subject to a constraint that the return difference does not exceed 1 bps. Returns to be matched are calculated using the closing stock prices on the day before the formation day and on the formation day. All portfolio returns are computed as value-weighted averages, using the formation day valuations of the matching stocks as weights for both the Matched-Return Sample and the DOTS Sample. The sample size is 46,275 stock-month observations for each of the two Samples. Column "High-Low" represents the results from buying the "High" portfolio and shorting the "Low" portfolio. ***, **, and * represent significance at the 1\%, 5\%, and 10\% levels, respectively. Newey and West (1987) standard errors are reported in parenthesis.

\begin{tabular}{|c|c|c|c|c|}
\hline $\begin{array}{c}\text { Holding } \\
\text { Period }\end{array}$ & Stocks & Low DOTS & High DOTS & High - Low \\
\hline \multirow{3}{*}{$t-1$} & DOTS Sample & $\begin{array}{l}0.287^{* * *} \\
(0.094)\end{array}$ & $\begin{array}{c}-0.397^{\text {*** }} \\
(0.089)\end{array}$ & $\begin{array}{l}0.683^{\text {*** }} \\
(0.054)\end{array}$ \\
\hline & Matched-Return Sample & $\begin{array}{l}0.287^{* * *} \\
(0.094)\end{array}$ & $\begin{array}{c}-0.397^{* * *} \\
(0.089)\end{array}$ & $\begin{array}{l}0.683^{\text {*** }} \\
(0.054)\end{array}$ \\
\hline & DOTS - Matched & 0.000 & 0.000 & 0.000 \\
\hline \multirow{3}{*}{$t$} & DOTS Sample & $\begin{array}{c}-0.337^{* *} \\
(0.138)\end{array}$ & $\begin{array}{l}0.607^{* * *} \\
(0.150)\end{array}$ & $\begin{array}{c}-0.944^{* * *} \\
(0.126)\end{array}$ \\
\hline & Matched-Return Sample & $\begin{array}{l}0.246^{* * *} \\
(0.092)\end{array}$ & $\begin{array}{l}0.304^{\text {*** }} \\
(0.107)\end{array}$ & $\begin{array}{r}-0.057 \\
(0.058)\end{array}$ \\
\hline & DOTS - Matched & $\begin{array}{c}-0.583^{\text {*** }} \\
(0.092)\end{array}$ & $\begin{array}{l}0.303^{* * *} \\
(0.093)\end{array}$ & $\begin{array}{c}-0.886^{* * *} \\
(0.129)\end{array}$ \\
\hline
\end{tabular}




\section{Table 6: DOTS predictability around earnings announcements}

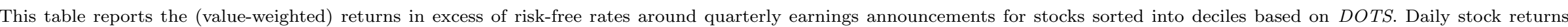

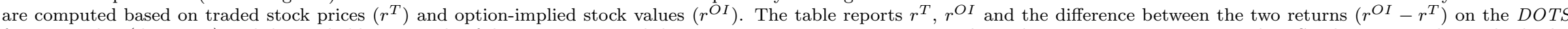

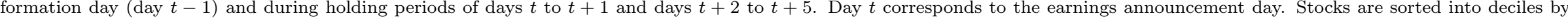

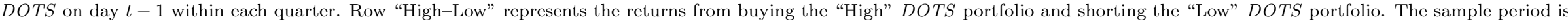
from 1996 to 2013 . ***,**, and * represent significance at the $1 \%, 5 \%$, and $10 \%$ levels, respectively. Newey and West (1987) standard errors are reported in parenthesis.

\begin{tabular}{|c|c|c|c|c|c|c|c|c|c|}
\hline & \multicolumn{3}{|c|}{ Formation Date Returns } & \multicolumn{6}{|c|}{ Holding Period Returns } \\
\hline & \multirow{2}{*}{$\frac{r^{T}}{t-1}$} & \multirow{2}{*}{$\frac{r^{O I}}{t-1}$} & \multirow{2}{*}{$\frac{r^{O I}-r^{T}}{t-1}$} & \multicolumn{2}{|c|}{$r^{T}$} & \multicolumn{2}{|c|}{$r^{O I}$} & \multicolumn{2}{|c|}{$r^{O I}-r^{T}$} \\
\hline & & & & $(t, t+1)$ & $(t+2, t+5)$ & $(t, t+1)$ & $(t+2, t+5)$ & $(t, t+1)$ & $(t+2, t+5)$ \\
\hline Low DOTS & $\begin{array}{l}0.898^{* * *} \\
(0.132)\end{array}$ & $\begin{array}{l}0.367^{\text {*** }} \\
(0.100)\end{array}$ & $\begin{array}{c}-0.531^{* * *} \\
(0.052)\end{array}$ & $\begin{array}{c}-0.194 \\
(0.173)\end{array}$ & $\begin{array}{c}0.253 \\
(0.209)\end{array}$ & $\begin{array}{c}0.310 \\
(0.192)\end{array}$ & $\begin{array}{c}0.153 \\
(0.178)\end{array}$ & $\begin{array}{l}0.504^{* * *} \\
(0.089)\end{array}$ & $\begin{array}{c}-0.099 \\
(0.080)\end{array}$ \\
\hline 2 & $\begin{array}{l}0.576^{* * *} \\
(0.100)\end{array}$ & $\begin{array}{l}0.305^{* * *} \\
(0.092)\end{array}$ & $\begin{array}{c}-0.272^{* * *} \\
(0.020)\end{array}$ & $\begin{array}{c}0.041 \\
(0.141)\end{array}$ & $\begin{array}{c}0.227 \\
(0.170)\end{array}$ & $\begin{array}{c}0.191 \\
(0.151)\end{array}$ & $\begin{array}{c}0.141 \\
(0.147)\end{array}$ & $\begin{array}{l}0.150^{* * *} \\
(0.045)\end{array}$ & $\begin{array}{r}-0.087^{*} \\
(0.051)\end{array}$ \\
\hline 3 & $\begin{array}{l}0.505^{* * *} \\
(0.070)\end{array}$ & $\begin{array}{l}0.339^{* * *} \\
(0.075)\end{array}$ & $\begin{array}{c}-0.166^{* * *} \\
(0.027)\end{array}$ & $\begin{array}{l}0.060 \\
(0.135)\end{array}$ & $\begin{array}{c}0.022 \\
(0.121)\end{array}$ & $\begin{array}{c}0.185 \\
(0.151)\end{array}$ & $\begin{array}{c}-0.040 \\
(0.127)\end{array}$ & $\begin{array}{l}0.125^{* * *} \\
(0.033)\end{array}$ & $\begin{array}{c}-0.062 \\
(0.041)\end{array}$ \\
\hline 4 & $\begin{array}{l}0.385^{* * *} \\
(0.094)\end{array}$ & $\begin{array}{l}0.299^{* * *} \\
(0.091)\end{array}$ & $\begin{array}{c}-0.086^{* * *} \\
(0.014)\end{array}$ & $\begin{array}{l}0.136 \\
(0.135)\end{array}$ & $\begin{array}{c}0.253^{*} \\
(0.145)\end{array}$ & $\begin{array}{c}0.184 \\
(0.136)\end{array}$ & $\begin{array}{c}0.182 \\
(0.132)\end{array}$ & $\begin{array}{l}0.048^{* *} \\
(0.023)\end{array}$ & $\begin{array}{c}-0.071 \\
(0.077)\end{array}$ \\
\hline 5 & $\begin{array}{l}0.367^{* * *} \\
(0.085)\end{array}$ & $\begin{array}{l}0.313^{* * *} \\
(0.091)\end{array}$ & $\begin{array}{c}-0.054^{*} \\
(0.029)\end{array}$ & $\begin{array}{c}0.093 \\
(0.143)\end{array}$ & $\begin{array}{c}0.153 \\
(0.113)\end{array}$ & $\begin{array}{c}0.110 \\
(0.130)\end{array}$ & $\begin{array}{c}0.110 \\
(0.107)\end{array}$ & $\begin{array}{c}0.017 \\
(0.034)\end{array}$ & $\begin{array}{c}-0.043 \\
(0.032)\end{array}$ \\
\hline 6 & $\begin{array}{l}0.272^{\text {*** }} \\
(0.070)\end{array}$ & $\begin{array}{l}0.234^{* * *} \\
(0.059)\end{array}$ & $\begin{array}{c}-0.037 \\
(0.041)\end{array}$ & $\begin{array}{c}0.245 \\
(0.171)\end{array}$ & $\begin{array}{c}0.012 \\
(0.113)\end{array}$ & $\begin{array}{c}0.152 \\
(0.159)\end{array}$ & $\begin{array}{c}-0.001 \\
(0.129)\end{array}$ & $\begin{array}{c}-0.094^{* *} \\
(0.045)\end{array}$ & $\begin{array}{c}-0.012 \\
(0.045)\end{array}$ \\
\hline 7 & $\begin{array}{c}0.038 \\
(0.056)\end{array}$ & $\begin{array}{c}0.099^{*} \\
(0.054)\end{array}$ & $\begin{array}{l}0.062^{* * *} \\
(0.023)\end{array}$ & $\begin{array}{c}0.301 \\
(0.203)\end{array}$ & $\begin{array}{c}0.186 \\
(0.157)\end{array}$ & $\begin{array}{c}0.173 \\
(0.189)\end{array}$ & $\begin{array}{c}0.145 \\
(0.151)\end{array}$ & $\begin{array}{c}-0.128^{* * *} \\
(0.026)\end{array}$ & $\begin{array}{c}-0.041 \\
(0.045)\end{array}$ \\
\hline 8 & $\begin{array}{c}-0.159^{* * *} \\
(0.047)\end{array}$ & $\begin{array}{c}-0.023 \\
(0.050)\end{array}$ & $\begin{array}{l}0.136^{* * *} \\
(0.034)\end{array}$ & $\begin{array}{c}0.144 \\
(0.182)\end{array}$ & $\begin{array}{c}0.065 \\
(0.169)\end{array}$ & $\begin{array}{c}0.051 \\
(0.182)\end{array}$ & $\begin{array}{r}-0.040 \\
(0.152)\end{array}$ & $\begin{array}{c}-0.093^{* * *} \\
(0.026)\end{array}$ & $\begin{array}{c}-0.105^{* *} \\
(0.043)\end{array}$ \\
\hline 9 & $\begin{array}{c}-0.420^{* * *} \\
(0.132)\end{array}$ & $\begin{array}{c}-0.202 \\
(0.134)\end{array}$ & $\begin{array}{l}0.219^{* * *} \\
(0.018)\end{array}$ & $\begin{array}{l}0.472^{* *} \\
(0.218)\end{array}$ & $\begin{array}{c}0.144 \\
(0.126)\end{array}$ & $\begin{array}{c}0.247 \\
(0.211)\end{array}$ & $\begin{array}{c}0.097 \\
(0.127)\end{array}$ & $\begin{array}{c}-0.225^{* * *} \\
(0.054)\end{array}$ & $\begin{array}{r}-0.047^{*} \\
(0.026)\end{array}$ \\
\hline High DOTS & $\begin{array}{c}-0.669^{* * *} \\
(0.154)\end{array}$ & $\begin{array}{c}-0.181 \\
(0.150) \\
\end{array}$ & $\begin{array}{l}0.488^{* * *} \\
(0.039)\end{array}$ & $\begin{array}{l}0.955^{* * *} \\
(0.204)\end{array}$ & $\begin{array}{c}0.043 \\
(0.192) \\
\end{array}$ & $\begin{array}{c}0.343^{*} \\
(0.189) \\
\end{array}$ & $\begin{array}{c}0.089 \\
(0.185) \\
\end{array}$ & $\begin{array}{c}-0.612^{* * *} \\
(0.058)\end{array}$ & $\begin{array}{c}0.047 \\
(0.064) \\
\end{array}$ \\
\hline High-Low & $\begin{array}{c}-1.566^{* * *} \\
(0.234)\end{array}$ & $\begin{array}{c}-0.548^{* *} \\
(0.208)\end{array}$ & $\begin{array}{l}1.019^{* * *} \\
(0.082)\end{array}$ & $\begin{array}{l}1.149^{* * *} \\
(0.225)\end{array}$ & $\begin{array}{c}-0.210 \\
(0.218)\end{array}$ & $\begin{array}{c}0.033 \\
(0.224)\end{array}$ & $\begin{array}{c}-0.064 \\
(0.197)\end{array}$ & $\begin{array}{c}-1.116^{* * *} \\
(0.131)\end{array}$ & $\begin{array}{c}0.146 \\
(0.106)\end{array}$ \\
\hline
\end{tabular}




\section{Appendix A Variable definitions}

In the table below we provide detailed descriptions of the variables used throughout the paper, which have been constructed from the sample described in Section 4.

\begin{tabular}{|c|c|}
\hline Variable Name & Definition \\
\hline$\triangle I V S$ & $\begin{array}{l}\text { Change in call minus put implied-volatility spread over the month ending on the } \\
\text { DOTS formation date. Implied volatility is measured as the smoothed implied } \\
\text { volatility of a } 30 \text {-day, at-the-money ( } \mid \text { delta } \mid=50 \%) \text { option. }\end{array}$ \\
\hline Abnormal OOI & $\begin{array}{l}\text { Option order imbalance }(O O I) \text { on the DOTS formation date in excess of the } \\
\text { average daily option order imbalance ratio over the period starting } 41 \text { trading } \\
\text { days and ending } 11 \text { trading days before the formation date. Available for April } \\
2008 \text { to December } 2013 \text { only. }\end{array}$ \\
\hline Abnormal SOI & $\begin{array}{l}\text { Stock order imbalance }(S O I) \text { on the DOTS formation date in excess of the } \\
\text { average daily stock order imbalance ratio over the period starting } 41 \text { trading days } \\
\text { and ending } 11 \text { trading days before the formation date. Available for NYSE-listed } \\
\text { stocks only. }\end{array}$ \\
\hline Abnormal TURN & $\begin{array}{l}\text { Abnormal stock turnover on the DOTS formation date in excess of the average } \\
\text { daily stock turnover over the period starting } 41 \text { trading days and ending } 11 \\
\text { trading days before the formation date. }\end{array}$ \\
\hline Amihud Illiquidity & Amihud (2002) illiquidity measure over the formation month. \\
\hline Calls (Puts): \# days since last trade & $\begin{array}{l}\text { Number of calendar days since options were last traded. Computed as } \\
\text { equal-weighted average across option contracts. }\end{array}$ \\
\hline$C P P$ & $\begin{array}{l}\text { Composite proxy for price pressure constructed as the sum of the percentile ranks } \\
\text { of a stock's return, SOI, signed Truncated Abnormal TURN, and signed bid-ask } \\
\text { spread. }\end{array}$ \\
\hline Idiosyncratic volatility & $\begin{array}{l}\text { Annualized standard deviation of regression residuals of daily stock excess returns } \\
\text { in the sorting month regressed on the five Fama and French (2015) factors. }\end{array}$ \\
\hline$I V S$ & $\begin{array}{l}\text { Difference between call and put implied volatility. Computed as weighted average } \\
\text { over option pairs using the sum of call and put open interest as weights. }\end{array}$ \\
\hline Market cap & Stock price times the number of shares outstanding on the DOTS formation date. \\
\hline \multirow[t]{2}{*}{$O O I$} & $\begin{array}{l}\text { Option order imbalance. Following Hu (2014), this is defined for stock } i \text { on day } t \\
\text { as follows: } \\
\qquad \text { OOI }_{i, t} \equiv \frac{\sum_{j=1}^{n} \operatorname{dir}_{i t j} \cdot \operatorname{delta}_{i t j} \cdot \operatorname{size}_{i t j}}{\sum_{j=1}^{n}\left|\operatorname{delta}_{i t j}\right| \cdot \operatorname{size}_{i t j}}\end{array}$ \\
\hline & $\begin{array}{l}\text { where } \operatorname{dir}_{i t j} \text { is a dummy variable equal to one (negative one) if the } j \text { th option } \\
\text { trade is initiated by the buyer (seller) according to a trade signing algorithm, } \\
\text { delta }_{i t j} \text { is the option price's sensitivity to the underlying stock price, and size } i t j \\
\text { is the trade size in option lots (one hundred shares of the underlying stock). We } \\
\text { normalize the OOI measure by the share-equivalent option volume. Available for } \\
\text { the OPRA sample only (April } 2008 \text { - December 2013). }\end{array}$ \\
\hline$S^{L}\left(S^{U}\right)$ & $\begin{array}{l}\text { Lower bound given in Equation (1) (upper bound given in Equation (2)). } \\
\text { Computed as the weighted average over all option pairs, using the inverse of the } \\
\text { option pair's bid-ask spread as weights. }\end{array}$ \\
\hline$S O I$ & $\begin{array}{l}\text { Stock order imbalance ratio: dollar value of buyer-initiated trades minus the } \\
\text { dollar value of seller-initiated trades on the DOTS formation date over the sum of } \\
\text { the dollar value of buyer-initiated trades and the dollar value of seller-initiated } \\
\text { trades on the DOTS formation date. Available for NYSE-listed stocks only. }\end{array}$ \\
\hline Truncated Abnormal TURN & Equal to the maximum of Abnormal TURN and zero. \\
\hline TURN & $\begin{array}{l}\text { Stock turnover: the dollar value traded on a particular day as a fraction of the } \\
\text { Market Cap. }\end{array}$ \\
\hline
\end{tabular}




\title{
Why Do Option Prices Predict Stock Returns? The Role of Price Pressure in the Stock Market
}

\author{
INTERNET APPENDIX \\ Luis Goncalves-Pinto, Bruce D. Grundy, Allaudeen Hameed, \\ Thijs VAN DER HeIJDEN, Yichao ZHU
}

May 10, 2019 


\section{IA.1 Stock mispricing and implied-volatility changes, spreads, and skews}

In this Appendix, we describe how stock mispricing relates to option-based predictors of stock returns, such as changes in the implied volatilities of calls and puts, the spread in implied volatilities between calls and puts, and implied volatility skews. These measures have been used in prior studies to predict future stock returns, and interpreted as a proxy for informed trading taking place in the options market before it takes place in the stock market. We argue instead that the stock return predictability associated with these measures is mechanically related to the degree of mispricing of the underlying stock that is not reflected in option quotes, and is not necessarily due to an asymmetry in information between the two markets.

\section{IA.1.1 Changes in implied volatilities}

Suppose one month ago a stock traded at its fundamental value and the option-implied volatility had been at its true unchanging value of $30 \%$. The monthly change in call optionimplied volatility will then be positive (negative) if the stock has become underpriced (overpriced) relative to its value by the end of the month. The opposite will be true for the

change in put option-implied volatility. The relation between the current level of mispricing of the stock and the change in option-implied volatility over the past month is as depicted in Figure IA.1. Figure IA.1 is a straightforward transformation of Figure 2 and depicts the monotone relation between the level of stock mispricing and the monthly change in option-implied volatility.

[Figure IA.1 about here] 


\section{IA.1.2 The implied-volatility spread}

The spread between the implied volatility of an at-the-money call and an at-the-money put provides another measure of stock mispricing. The volatility spread is monotonically increasing in the level of underpricing of the stock. Figure IA.2 shows that, for the parameters used to create the figure, a one percent mispricing of the stock leads to a near ten percent implied-volatility spread.

[Figure IA.2 about here]

The qualitative properties of the relations depicted in Figures 2 and IA.1 do not depend on whether option prices are determined by the Black-Scholes model.

\section{IA.1.3 The implied-volatility skew}

The volatility skew, also termed the volatility smirk, can be defined as the difference between the implied volatility of an out-of-the-money put and the implied volatility of an atthe-money call. Like the other volatility measures, the skew is a monotonic transformation of the level of stock mispricing. For the parameter values used to create it, Figure IA.3 shows how the difference between the implied volatility of an out-of-the-money put and an at-the-money call varies with the level of stock mispricing. ${ }^{1}$

[Figure IA.3 about here]

The qualitative properties of the relations depicted in Figures 2, IA.1 and IA.2 do not depend on whether option prices are determined by the Black-Scholes model. When option prices are determined by Black-Scholes and the stock is correctly priced, then the implied volatility skew is zero. But when option prices are not given by Black-Scholes, the implied

\footnotetext{
${ }^{1}$ The correlation between DOTS and the 1-month implied volatility skew measure used in Xing, Zhang, and Zhao (2010), defined as the difference between the implied volatility of a put option with delta equal to -0.2 and a call option with delta equal to 0.5 as given by the OptionMetrics Volatility Surface, equals -0.45 .
} 
volatility skew will be non-zero even for a correctly-priced stock. In that event the qualitative relation between the skew and mispricing as depicted in Figure IA.3 will be overlaid on the skew applicable when the stock is correctly priced. 


\section{References}

Xing, Y., X. Zhang, and R. Zhao. 2010. What does the individual option volatility smirk tell us about future equity returns? Journal of Financial and Quantitative Analysis 45:641662. 


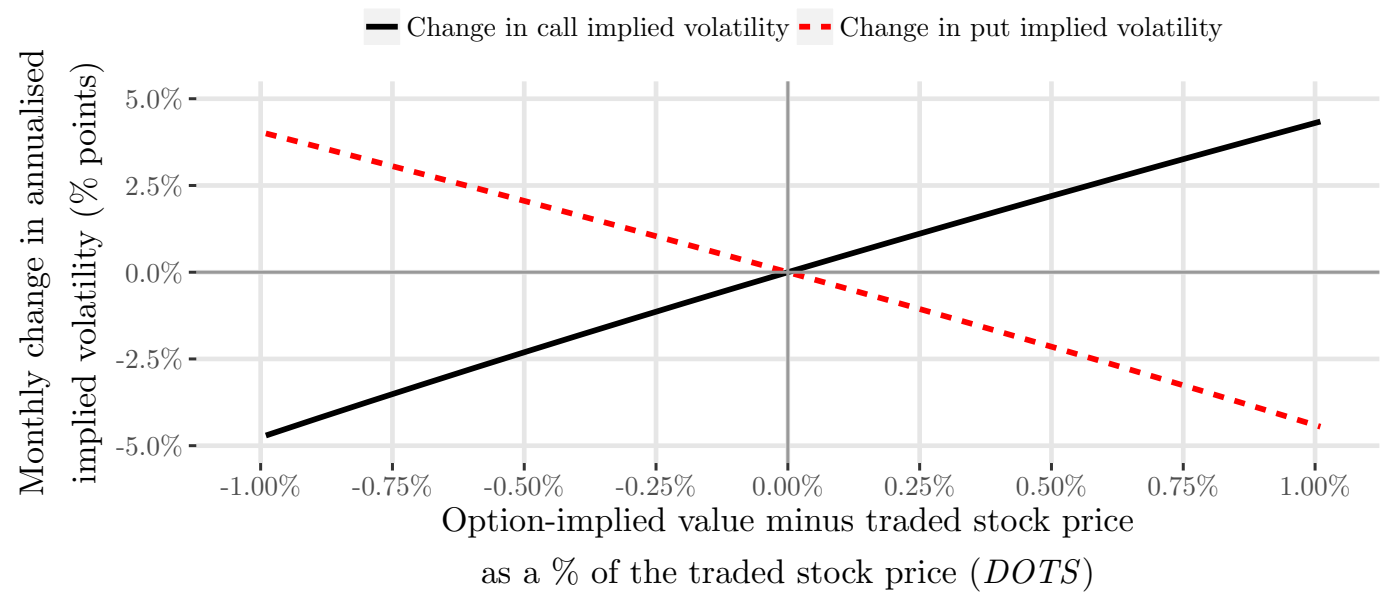

\section{Figure IA.1: Changes in at-the-money call and put implied volatilities}

This figure plots monthly changes in the Black-Scholes implied volatilities of a call and a put option as a function of DOTS. The options have a strike price equal to the stock's fundamental value and a maturity of 1 month. The risk-free interest rate and the stock return volatility per annum are $0 \%$ and $30 \%$, respectively. The dollar option prices are computed by Black-Scholes using the stock's option-implied value as an input. The implied volatilities are computed from Black-Scholes using the traded stock price as the input. At the end of the prior month the stock is assumed to have traded at its option-implied value. The traded stock price at the end of the current month can deviate from the option-implied value.

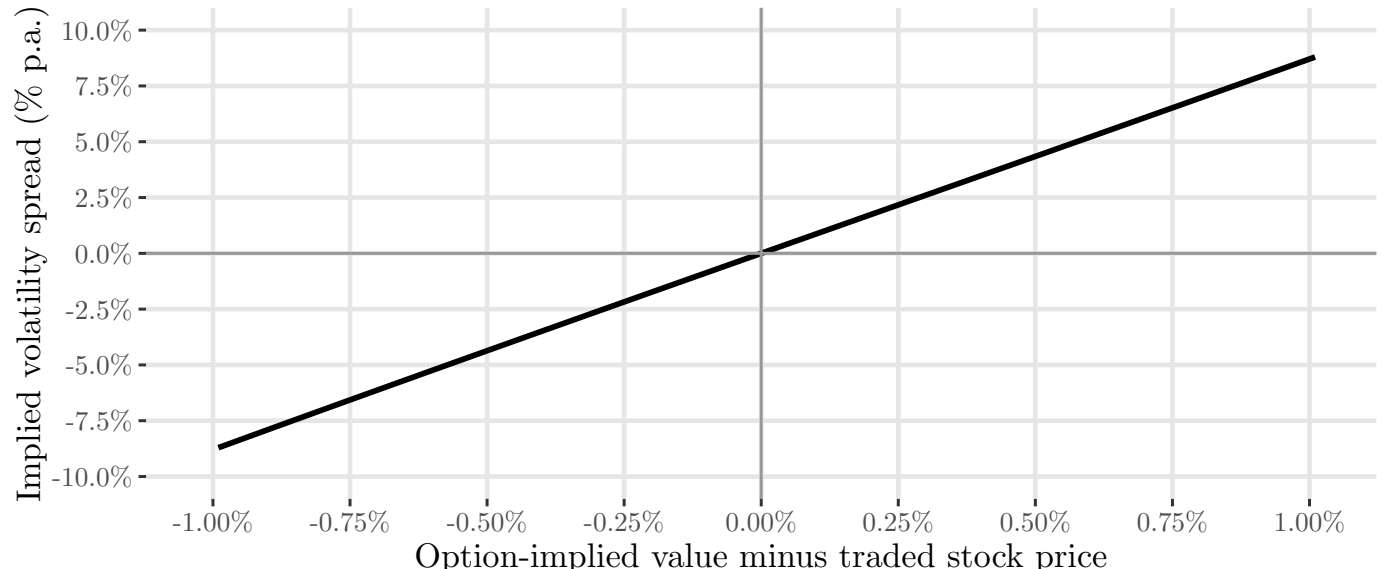

as a $\%$ of the traded stock price $(D O T S)$

\section{Figure IA.2: Spread between at-the-money call and put implied volatilities}

This figure plots the difference in the Black-Scholes implied volatilities of a call and a put option as a function of DOTS. The options have a strike price equal to the stock's fundamental value and a maturity of 1 month. The risk-free interest rate and the stock return volatility per annum are $0 \%$ and $30 \%$, respectively. The dollar option prices are computed by Black-Scholes using the stock's option-implied value as an input. The implied volatilities are computed from Black-Scholes using the traded stock price as the input. 


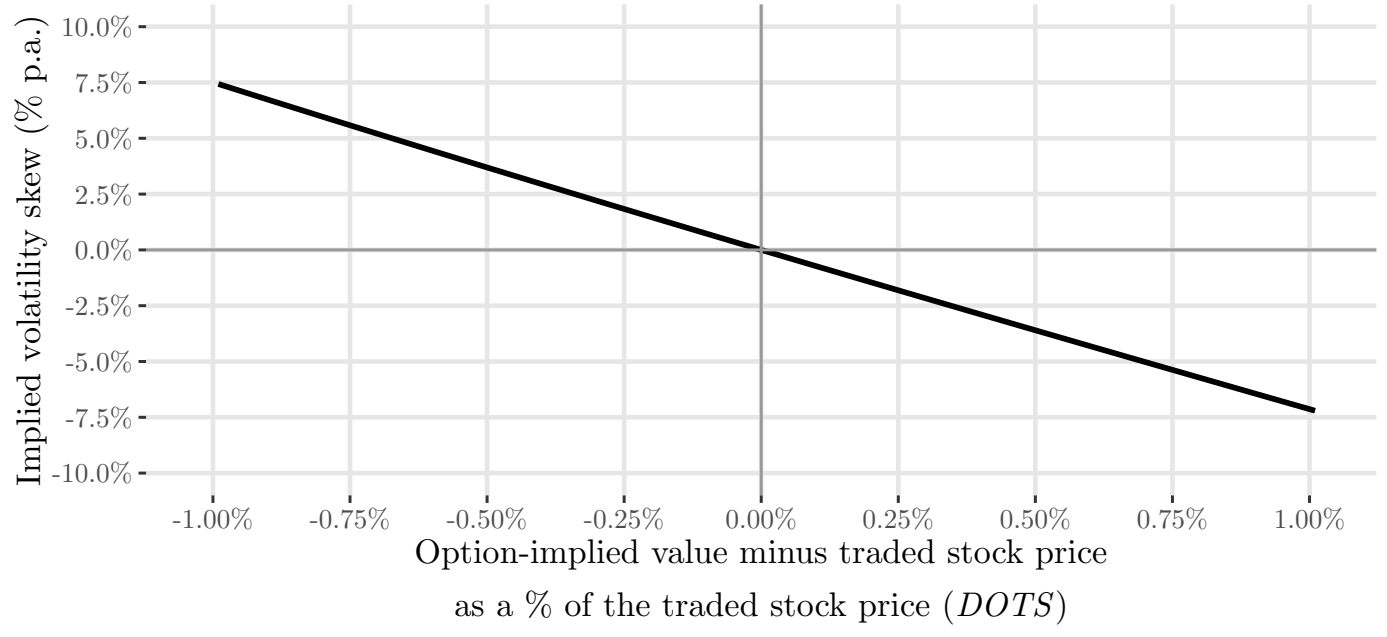

Figure IA.3: Difference between implied volatility of out-of-the-money put and at-themoney call

This figure plots a proxy for the implied volatility skew as a function of DOTS. The proxy is calculated as the difference between the Black-Scholes implied volatility of an out-of-the-money put option and the Black-Scholes implied volatility of an at-the-money call option. The out-of-the-money put option's strike price equals 0.95 times the stock's fundamental value, and the at-the-money option's strike price equals the stock's option-implied value. All options have a maturity of 1 month. The risk-free interest rate and the stock return volatility per annum are $0 \%$ and $30 \%$, respectively. The dollar option prices are computed by Black-Scholes using the stock's option-implied value as an input. The implied volatilities are computed from Black-Scholes using the traded stock price as the input. 